\title{
LIDERANÇA E AUTONOMIA NAS NOVAS FORMAS DE ORGANIZAÇÃO DO TRABALHO: COMPARANDO EMPRESAS DO PORTO DIGITAL DE PERNAMBUCO
}

\author{
LEADERSHIP AND AUTONOMY IN NEW FORMS OF WORK ORGANIZATION: \\ COMPARING COMPANIES FROM THE DIGITAL PORT OF PERNAMBUCO
}

\author{
VERA LÚCIA DA CONCEIÇÃO NETO \\ Professora Adjunta da Universidade Federal do Espírito Santo \\ Doutora em Administração \\ Orcid: https://orcid.org/0000-0001-9363-8414 \\ E-mail: vera.neto@imparrh.com.br \\ GUILHERME LIMA MOURA \\ Professor Associado da Universidade Federal de Pernambuco \\ Doutor em Linguística \\ Orcid: http://orcid.org/0000-0003-2729-5286 \\ E-mail: glmoura@gmail.com \\ Av. dos Funcionários, s/n - CCSA - Cidade Universitária - PE - Brasil \\ CEP: $50.740-580$
}

\begin{abstract}
RESUMO
Este artigo apresenta os resultados de uma pesquisa sobre construção da autonomia no ambiente de trabalho em Novas Formas de Organização do Trabalho (NFOT). Especificamente, analisou como a autonomia dos funcionários se estrutura na relação com os líderes em duas empresas de Tecnologia da Informação (TI), situadas no Porto Digital de Pernambuco. Nas NFOT, a liderança e a autonomia dos liderados são questões centrais das relações interpessoais no ambiente organizacional carregadas de conflitos, poder, contradições, motivações, mediações e busca pela eficiência. A abordagem teórica assume as NFOT como organizações burocráticas, que se distinguem por (supostamente) incorporarem com mais intensidade: flexibilidade; inovação; horizontalização da estrutura; foco em competências; trabalho em equipe; envolvimento e participação dos profissionais (CLEGG; HARRIS; HÖPFL, 2011; KOVÁCS, 2006). Compreende a liderança como uma proposta de linguagem, propriedade não exclusiva dos líderes formais, espaço de um processo de construção das relações através de negociações, renegociações, reconstruções, ressignificados (HOSKING, 1988; HOSKING; DACHLER, 1995; HOSKING, 2006). A pesquisa foi qualitativa, cujos dados foram obtidos através de vinte entrevistas semiestruturadas, aplicadas a líderes e liderados de duas empresas de $\mathrm{TI}$, e submetidos à Análise Crítica do Discurso (FAIRCLOUGH, 2019). Foi constatado que organizações vistas como NFOT nem sempre são ambientes de estímulo à autonomia. Por outro lado, numa mesma organização, práticas flexíveis da liderança podem coexistir com práticas tradicionais de controle burocrático. O líder tem um papel fundamental, uma vez que sua personalidade pode imbricar na estrutura organizacional um estímulo ao engajamento do poder.
\end{abstract}

Palavras-chave: Burocracia. Liderança. Autonomia. Empresas de TI.

Data de submissão: 19/03/2019. Data de aceite: 05/12/2019. Data de publicação: 20/12/2019. 


\begin{abstract}
This paper presents the results of a research on the construction of autonomy in the work environment in New Forms of Work Organization (NFWO). Specifically, it analyzed how the autonomy of the employees is structured in the relationship with the leaders in two companies of Information Technology (IT), at the Digital Port of Pernambuco. In the NFWO, the leadership and autonomy of the leaders are central questions of the interpersonal relations established in the organizational environment mixed with conflicts, power, contradictions, motivations, mediations and search for efficiency in work. In this sense, the theoretical approach of the article assumes the NFWO as bureaucratic organizations, which (supposedly) are distinguished by incorporating with more intensity practices of: flexibility; innovation; structure horizontalization; focus on skills; team work; involvement and participation of professionals (CLEGG; HARRIS; HÖPFL, 2011; KOVÁCS, 2006). Leadership is understood as a language proposal that is not exclusive to formal leaders, a space for building relations through negotiations, renegotiations, reconstructions, re-signified (HOSKING, 1988, DACHLER, 1995, HOSKING, 2006). The research was qualitative. Data were obtained through twenty semi-structured interviews, applied to leaders and subordinates of two IT companies and submitted to the Critical Discourse Analysis (FAIRCLOUGH, 2019). It was found that organizations seen as NFWO are not always autonomous environments. On the other hand, in one organization, flexible leadership practices can coexist with traditional bureaucratic control practices. The leader has a fundamental role, since his personality can imbricate in the organizational structure a stimulus to the engagement of the power.
\end{abstract}

Keywords: Bureaucracy. Leadership. Autonomy. IT companies.

\title{
1 INTRODUÇÃO
}

As mudanças no mercado econômico decorrentes também da globalização e das inovações tecnológicas, que se intensificaram durante o século XX, tornaram o ambiente organizacional turbulento. Essas mudanças exigiram maior velocidade, competitividade e dinamismo das organizações, e a tradicional burocracia inflexível não gerava mais respostas para solucionar os problemas, precisando ser substituída por novas práticas organizacionais (PALMER; DUNFORD, 2002; DUNFORD et al., 2007). Além disto, o mundo virtual e as redes direcionadas para a democratização das relações sociais (TENÓRIO, 2002) requisitaram práticas nomeadas pós-burocráticas projetadas para a flexibilidade da estrutura organizacional, propondo uma forma de gestão diferente como meio de adaptação à nova conjuntura (PALMER; BENVENISTE; DUNFORD, 2007).

Diante deste cenário, ainda no século XX emergiram as chamadas novas formas organizacionais (NFOs). Elas apresentaram diversos enfoques, em que foram discutidas questões como inteligência organizacional (PINCHOT; PINCHOT, 1994; QUINN, 1992), flexibilidade e inovação organizacional (COHENDET; LLERENA, 1999; NADLER; TUSHMAN 1999; TARONDEAU, 1999; VOLBERDA, 1996), emergência de novos paradigmas nos estudos organizacionais (CLEGG, 1998; COOPER, BURRELL, 1988; PARKER, 1992; TSOUKAS, 1992); empowerment (CONGER; CANUNGO, 1988; D'ANNUNZIO-GREEN; MACANDREW, 1999; HERRENKOHL; JUDSON; HEFFNER, 1999; SMITH; MOULY, 1998; THOMAS; VELTHOUSE, 1990), aprendizagem na organização (ARGYRIS, 1957), autogestão (PURSER; CABANA, 1998), 
competências (LE BOTERF, 1995; SPENCER; SPENCER, 1993; ZARIFIAN, 1999a) e autonomia no trabalho (EVERAERE, 1999a, 1999b; TERSSAC, 1999).

Das NFOs emergiram as novas formas de organização do trabalho (NFOT), expressão que foi utilizada na Europa desde 1970. Nas NFOT foram destacadas duas perspectivas: a renovação da estrutura organizacional e a humanização do trabalho. A renovação da estrutura organizacional implicou em uma flexibilidade da gestão, propondo a substituição de estruturas com hierarquias rígidas por outras mais inovadoras e flexíveis, ressaltando a competência, o trabalho em equipe, a participação e a autonomia (GERGEN; TOJO, 1996). Enquanto que a humanização do trabalho, de posicionamento mais crítico, propôs melhoria das condições de trabalho para os trabalhadores. As NFOT deveriam possibilitar maior participação nas decisões, aperfeiçoamento da qualidade do trabalho para todos os trabalhadores e maior segurança no trabalho em relação às consequências advindas das mudanças tecnológicas e organizacionais (KOVÁCS, 2006; ROSENFIELD, 2004; ROSENFIELD; ALVES, 2011).

O discurso sobre a renovação da estrutura organizacional pressupôs uma atuação diferenciada da liderança, em que o exercício da autonomia pelos trabalhadores recebeu um forte realce. Nas NFOT a estruturação é hierárquica, mas com horizontalização; existe a autoridade formal do líder simultaneamente com a distribuição do controle para o funcionário que favorece a concessão de maior autonomia.

No exercício da autonomia não se necessita de uma supervisão direta de um líder formal. As necessidades motivacionais e as possibilidades de negociações com o líder permitem que o indivíduo incorpore a autoadministração e a automonitorização, simbolicamente (CLEGG; HARRIS; HÖPFL, 2011). O discurso antiburocrático da flexibilidade possibilita que a organização economize estrutural e financeiramente com a concessão da autonomia, uma vez que o indivíduo torna-se burocrático de si mesmo em busca da autoeficiência e da produtividade.

Importante ressaltar que algumas discussões críticas advogam que as NFOT são uma reafirmação das estruturas burocráticas, um novo aparato da hierarquia e dos controles organizacionais. Alguns debates se concentram na afirmação de que as velhas formas burocráticas existem, mas podem ser alinhadas com as novas formas de flexibilização (PALMER; DUNFORD, 2002; DUNFORD et al., 2007; PALMER; BENVENISTE; DUNFORD, 2007). Porém, outras contestações indicam que as NFOT apresentam como consequência a fragmentação do trabalho (KALLINIKOS, 2003), enfraquecendo o coletivo, pois são novos arranjos da burocracia chamados de práticas pós-burocráticas ou neoburocráticas com uma estrutura mais sutil (ANDRADE; TOLFO; DELLAGNELO, 2012; CLEGG; HARRIS; HÖPFL, 2011; COURPASSON, 2000a; DELLAGNELO; MACHADO-DA-SILVA, 2000).

Diante destes argumentos, as práticas flexíveis de gestão sustentadas pelo aparato tecnológico requerem a autonomia nas NFOT e exigem outras relações e interações entre líderes e liderados. Os ambientes com maior potencial de práticas flexíveis, como por exemplo, as empresas de Tecnologia da Informação (TI) requisitam maior qualificação e habilidades técnicas, iniciativa e responsabilidade dos profissionais. A constante inovação e concorrência, a qualidade e a diversificação de produtos (EL ANDOULSI, 2012) demandam um nível elevado de autonomia, uma vez que os profissionais lidam com recursos tecnológicos cada vez mais avançados (MAZMANIAN; ORLIKOWSKI; YATES, 2013) e serviços que implicam diretamente na satisfação dos clientes (ZARIFIAN, 1999a).

Isso nos leva ao fato de que, nas NFOT, a liderança e a autonomia dos liderados são questões centrais das relações interpessoais estabelecidas no ambiente organizacional 
carregadas de conflitos, poder, contradições, motivações, mediações, interações sociais, interculturais e busca pela eficiência no trabalho (BENDASSOLLI; MAGALHÃES; MALVEZZI, 2014; FONSECA; PORTO; BORGES-ANDRADE, 2015; MALVEZZI, 2019; TURANO; CAVAZOTTE, 2016).

Assim sendo, surgiu o interesse em compreender como se estrutura a relação entre o líder e o liderado, articulando-se o desenvolvimento da autonomia nas NFOT especificamente em empresas de Tl. A escolha desse corpus se caracteriza pelo fato de que as empresas de $\mathrm{TI}$ são indicadas como exemplos de NFOT, por possuírem ambientes de trabalho considerados mais flexíveis. O objetivo deste artigo, então, é analisar a construção da autonomia no ambiente de trabalho em NFOT, considerando-a especificamente na relação com os líderes em duas empresas de TI do Porto Digital de Pernambuco.

Uma vez problematizada a nossa questão central nesta introdução, passamos a discutir sucintamente a perspectiva teórica que usamos para definir os conceitos de NFO e NFOT (seção 2), de liderança (seção 3) e de autonomia (seção 4). Em seguida, detalhamos os procedimentos metodológicos que nos levam da problematização inicialmente introduzida ao confronto com o corpus sob investigação (seção 5). Apresentamos, então, a análise dos dados obtidos por meio de vinte entrevistas semiestruturadas, aplicadas a líderes e liderados, e submetidos à Análise Crítica do Discurso (FAIRCLOUGH, 2019) (seção 6). Por fim, concluímos nosso texto com uma reflexão sobre as práticas de autonomia que surgem - ora a partir, ora apesar - da estrutura construída pela liderança, mesmo em representantes notórios das Novas Formas de Organização do Trabalho (seção 7).

\section{AS NOVAS FORMAS ORGANIZACIONAIS (NFOS) E AS NOVAS FORMAS DE ORGANIZAÇÃO DO TRABALHO (NFOT)}

Primeiramente, o conceito de 'forma organizacional' se refere às características de uma organização. As características identificam a organização como uma unidade distinta e ao mesmo tempo permite considerá-la como uma parte de um grupo organizacional similar (ROMANELLI, 1991). As formas de organização consideradas tradicionais possuem os papéis definidos claramente, têm a divisão de tarefas, as regras são rígidas, a hierarquia é predominante e a autoridade é destinada ao equilíbrio do sistema em resposta a representação de um ideal de eficácia (GUNIA, 2002). As NFOs surgiram como uma objeção às formas tradicionais.

Nas NFOs existem dois posicionamentos teóricos em relação à mudança. O primeiro posicionamento adota que as NFOs são uma mudança revolucionária, uma vez que as práticas de flexibilidade são incompatíveis com as de estabilidade, pois exigem outras demandas e melhorias operacionais radicais no ambiente de negócio e na tecnologia da informação para dar suporte à estrutura, aos processos e à tomada de decisão. Então, as novas configurações substituiriam o modelo burocrático. O segundo posicionamento assume que as NFOs são uma mudança evolucionária originária das estruturas tradicionais que recombinam as práticas antigas com as novas (PALMER; BENVENISTE; DUNFORD, 2007). É mais uma regulação econômica (FOSS, 2002) que envolve a relação existente entre estratégia, estrutura e mercado. No posicionamento evolucionário se pressupõe que o velho e o novo podem coexistir na mesma organização (PALMER; BENVENISTE; DUNFORD, 2007; DUNFORD et al., 2007).

Os dois posicionamentos teóricos marcaram as NFOT de um lado como uma oposição ao taylorismo e à burocracia chamadas de práticas pós-burocráticas; e de outro, como uma mera continuação da burocracia. A oposição no fato de que a organização racional do trabalho 
se concentrou na divisão do trabalho, no controle, na disciplina, na fragmentação das tarefas e na obediência às regras. $E$ as práticas pós-burocráticas trazem a flexibilidade e a autonomia para a execução das tarefas, confiando ao funcionário responsabilidades e cedendo o grau de controle sobre ele. Pelo ângulo de visão de um continuum da burocracia, a ênfase na flexibilidade e na autonomia é mais uma manobra de controle para redução dos custos da empresa, uma vez que a flexibilidade funcional se refere ao alargamento da tarefa (job enlargement), à rotação do posto de trabalho (job rotation) e à reengenharia de processos, enquanto que a autonomia está associada ao enriquecimento da tarefa (job enrichment), aos círculos de qualidade e às equipes de trabalho (CHÊNEVERT; DUBÉ, 2008).

Ressalta-se que as práticas pós-burocráticas ou NFOT se apoiam simultaneamente na tecnologia e no fator humano para promover a descentralização e o tipo de grau de autonomia aplicado às pessoas. As NFOT se fundamentam em técnicas consideradas flexíveis como a multi-habilidades, autonomia no trabalho, rodízio de função, participação na decisão, trabalho em equipe e são apresentadas como as melhores práticas de geração de resultados positivos referentes à motivação, ao desempenho, à identidade e à satisfação (CAPPELLI; ROGOVSKI, 1998).

Na realidade, a evolução da organização do trabalho desde a científica até a pósburocrática tornou o trabalho mais variado e mais complexo para o indivíduo. $\mathrm{O}$ trabalho na pós-burocracia está mais rico em conteúdo e em natureza devido a uma demanda maior de investimento subjetivo e de mobilização da inteligência, além de competências diversas, da cooperação e do exercício da autonomia (CHÊNEVERT; DUBÉ, 2008; ROSENFIELD; ALVES, 2011).

\section{LIDERANÇA: ABORDAGENS CONTEMPORÂNEAS}

As abordagens contemporâneas contextualizam a liderança como um relacionamento, um processo de influência e reciprocidade entre líder e liderado. Elas estão agrupadas da seguinte forma: liderança distribuída, enfocando o poder distribuído (GRONN, 2000; SPILLANE; HALVERSON; DIAMOND, 2001; ROSS; RIX; GOLD, 2005); liderança relacional, enfatizando a questão das relações (UHL-BIEN, 2006) e liderança como processo de construção social, abordando que as múltiplas realidades são construídas pelos atores envolvidos (HOSKING, 1988, 2006).

A liderança distribuída não é derivada simplesmente de ações individuais. É um produto das interações existentes entre o líder, os seguidores e os aspectos da situação (GRONN, 2000; SPILLANE; HALVERSON; DIAMOND, 2001). No que concerne, a prática de liderança e gestão é "esticada para dois ou mais líderes e seguidores" (SPILLANE; HALVERSON; DIAMOND, 2001, p. 25), e a situação oferece informações, como por exemplo, ferramentas de vários tipos, estruturas organizacionais, rotinas, linguagem que contribuem para estabelecer a prática de liderança como um processo de interação entre as pessoas (SPILLANE; SHERER, 2004). Portanto, a liderança distribuída é considerada como um fenômeno coletivo. Ela ocorre dentro de ações e atividades que se estendem entre diferentes atores, e estes podem exercer influências diversas sobre uma situação.

A liderança relacional possibilita o estudo da dinâmica relacional, focando os processos relacionais em que a liderança é produzida e habilitada. Ela não define liderança como detentora de uma posição gerencial (BEDEIAN; HUNT, 2006; HOSKING, 1988). A liderança pode ocorrer em qualquer direção, em algumas situações pode resultar na quebra da distinção entre quem conduz e quem é conduzido (ROST, 1995), refletindo um processo de 
influência mútua (HOLLANDER, 1978; GRAEN; UHL-BIEN, 1991; UHL-BIEN; GRAEN; SCANDURA, 2000).

Partindo desses fundamentos relacionais, surge a liderança como um processo de construção social. As pesquisas direcionadas para o entendimento do que os líderes fazem não são suficientes para investigar o fenômeno da liderança. Hosking (1988) argumenta que os pesquisadores devem se concentrar em 'processos'. Significa compreender os atos influentes na organização que contribuem para a estruturação de interações e relacionamentos. Nesses processos, as interdependências são organizadas de forma que, em maior ou menor grau, possam promover os valores e interesses da ordem social, em que suas definições sejam negociadas, consideradas aceitáveis, implementadas e renegociadas (HOSKING, 1988; HOSKING; DACHLER, 1995).

Um ato de liderança pode implicar em múltiplas referências simultâneas à hierarquia, à identidade, ao poder individual ou compartilhado, à missão, à responsabilidade organizacional talvez nacional, cultural, de relações, de negócios, entre outros. O processo pode deixar realidades relacionais implícitas, explícitas, presas aos jogos de poder, às racionalidades de culturas locais ou acrescentar situações novas. Ele varia na medida em que surgem possibilidades, desenvolve-se e realimenta-se pela própria continuidade das relações (HOSKING, 2006).

O processo não se inicia com a liderança. Os participantes não estão relacionados como 'receptáculos passivos' ou como 'imaginativos consumidores' que absorvem as mensagens culturais emanadas pelas organizações (BRYMAN, 2004, p. 273). Todos os participantes são potencialmente ativos contribuintes para as realidades locais. Esses processos podem deixar espaço para os participantes gerarem múltiplas realidades culturais e locais (HOSKING, 2006; SOBRAL, F.; FURTADO, 2019; VILAS-BOAS; DAVEL, 2018).

\section{AUTONOMIA NOS ESTUDOS ORGANIZACIONAIS}

A autonomia é inerente à vida humana, é a norma do sujeito que se origina no próprio sujeito. $\mathrm{O}$ termo autonomia é de origem grega, etimologicamente grafada como autos (por si mesmo), significando "o poder de dar a si a própria lei" e nomós que possui duas interpretações: lei e simultaneamente, território (ZATTI, 2007). No sentido geral, a "autonomia é a condição de uma pessoa ou de uma coletividade autônoma, que determine ela mesma a lei à qual se submete" (LALANDE, 2006, p. 101).

A autonomia se caracteriza como um processo de reflexão que gera ideias próprias. É um processo ativo associado à atividade racional. Esse processo contempla leis e regras que dirigem e governam uma ação como uma fonte de regulação entre o individual e o coletivo. Compatibiliza diferentes leis individuais que surgem (ALEXANDRE-BAILLY, 2011) decorrentes da exigência e da necessidade de liberdade. Esta liberdade está condicionada por uma moral que deve visar o bem coletivo na sua dimensão política-social. O poder de se organizar no coletivo e de administrar certas regras têm certos limites. A autonomia é uma fonte de criação e de transformação, pois possibilita criar novas regras ou condições que constituam uma mudança social (CASTORIADIS, 2007).

Diante disto, a preocupação com o funcionamento e as características das organizações instituídas, originou uma variedade de estudos e observações decorrentes da natureza, dos temas e dos problemas existentes. Os estudos organizacionais geraram inúmeras teorias administrativas conforme cada período histórico. Compartilha-se da ideia de que existe uma "selva" de teorias organizacionais (ESCRIVÃO FILHO; GUERRINI, 2010), mas que ao considerar os pressupostos teóricos observam-se quatro grandes escolas de 
pensamento distinguidas como Clássica, Relações Humanas, Sistêmica e Contingencial decorrentes de movimentos teóricos que ajudam no entendimento da ideia de autonomia. Porém, entre as escolas surgem as abordagens, tais como a sociotécnica, a sociológica, a 'empowerment era' identificada como a era do empoderamento (HARDY; LEIBA-O'SULLIVAN, 1998) e as ideias sobre comportamento pró-ativo e competências.

Os movimentos teóricos e as abordagens possibilitam identificar as concepções sobre a autonomia. Iniciando pela sua rejeição, em seguida o seu reconhecimento, a sua nova rejeição, o seu ressurgimento e novo reconhecimento, e por último a sua valorização como construto. Desta forma, observa-se uma evolução dos conceitos da autonomia para a ação estratégica, a complexidade, a pró-atividade e as competências.

Exibe-se o Quadro 1 com o resumo geral sobre a visão de autonomia contemplando os movimentos organizacionais e as abordagens com seus aportes teóricos mais significativos.

Quadro 1 - Resumo geral sobre a visão de autonomia nos movimentos organizacionais

\begin{tabular}{|c|c|}
\hline \multicolumn{2}{|c|}{ Movimento de Racionalização do Trabalho (1900 a 1930): a rejeição da autonomia } \\
\hline Autores & Visão sobre Autonomia \\
\hline Taylor (1903) & Um sinal de desobediência e de comportamentos contraprodutivos. \\
\hline Fayol (1919) & Um risco, um perigo, uma perturbação para o sistema de produção. \\
\hline Weber (1924) & A autonomia é suprimida pelo sistema burocrático. \\
\hline \multicolumn{2}{|c|}{ Movimento de Relações Humanas (1930 a 1950): reconhecimento da autonomia } \\
\hline Georges Elton Mayo (1924) & Autonomia como fonte de motivação. \\
\hline Abraham Maslow (1954) & Autonomia como necessidade de autorrealização. \\
\hline Chris Argyris (1957) & Autonomia como capacidade de aprendizagem. \\
\hline Douglas McGregor (1960) & Autonomia como participação na tomada de decisão. \\
\hline David McClelland (1961) & Autonomia como necessidade essencial do indivíduo. \\
\hline Frederick Herzberg (1959) & Enriquecimento de tarefas. \\
\hline \multicolumn{2}{|c|}{ Abordagem Desenho dos Cargos (1955 -): instrumentalização da autonomia } \\
\hline Turner e Lawrence (1965) & Atributo da tarefa requerida. \\
\hline Hackman e Lawler (1971) & Dimensões da satisfação no trabalho. \\
\hline Hackman e Oldham (1974) & Dimensões da satisfação no trabalho. \\
\hline Gulowsen (1972) & Dimensão que deve ser medida por graus hierarquicamente. \\
\hline Decotiis e Koys (1980) & Dimensão que influencia no clima organizacional. \\
\hline Kiggundu (1981) & Associada à interdependência da tarefa. \\
\hline Breaugh (1985) & Grau de controle sobre método, programação e critério do trabalho. \\
\hline Jackson et al. (1993) & $\begin{array}{l}\text { Liberdade de controle da programação, do tempo de trabalho, dos métodos e } \\
\text { dos procedimentos utilizados. }\end{array}$ \\
\hline $\begin{array}{l}\text { Morgeson e Humphrey } \\
\text { (2006) }\end{array}$ & Liberdade na programação de trabalho, tomada de decisão e métodos. \\
\hline $\begin{array}{l}\text { Lumpkin, Cogliser e } \\
\text { Schneider (2009) }\end{array}$ & Componente da orientação empreendedora. \\
\hline Rao e Venugopal (2009) & Elemento que promove a qualidade de vida. \\
\hline $\begin{array}{l}\text { Mazmanian, Orlikowski e } \\
\text { Yates (2013) }\end{array}$ & Capacidade dinâmica promulgada por trabalhadores em prática. \\
\hline \multicolumn{2}{|c|}{ Movimento dos Sistemas (1950 a 1965): nova rejeição da autonomia } \\
\hline Talcott Parsons (1960) & As decisões e as escolhas são influenciadas pelas normas sociais. \\
\hline \multicolumn{2}{|c|}{ Abordagem Sociotécnica (1960 -): ressurgimento da autonomia } \\
\hline Trist e Bamforth (1951) & $\begin{array}{l}\text { Autonomia responsável: as funções de liderança e de supervisão pertencem ao } \\
\text { grupo que autorregula-se para completar as tarefas. }\end{array}$ \\
\hline Emery (1969) & Potencial de auto-organização, autoideal e aprendizagem dos grupos. \\
\hline Dill (1958) & Processo decisório. \\
\hline Pugh et al. (1968) & Autonomia e o grau de centralização da organização. \\
\hline
\end{tabular}


Inkson, Pugh e Hickson

(1970)

Brock (2003)

Spector (1986)

Evans e Fischer (1992)

Manz e Sims (1980)

Knights e Willmott (2002)

Neck e Houghton (2006)

Deci e Ryan $(2004,2008)$
Autonomia e a concentração de autoridade.

Descentralização do trabalho.

Gestão participativa e controle sobre o trabalho.

Participação e percepção subjetiva de controle do trabalhador.

Autogerenciamento

Associada à tecnologia torna-se um controle da liderança.

Autoliderança.

Autodeterminação.

Abordagem Sociológica (1970 -): autonomia como ação estratégica

Crozier e Friedberg (1977) Ação estratégica do indívíduo limitada e contingencial.

Sainsaulieu (1977)

Reynaud (1988)

Associada à construção da identidade do individuo no trabalho.

Courpasson (2000b)

Força em constante negociação com o controle.

Ação restrita, porém relacionada à resistência.

\section{Movimento Contingencial (1965 a 1980): autonomia complexa}

Woodward (1958)

Burns e Stalker (1961)

Lawrence e Lorsch (1967)

Pugh, Hickson e Hininys (1969)

Mintzberg (2011)

Child (1972)

Pfeffer e Salancik (1978)

Johnson, Melin e Whittington

(2003)
Resultado das mudanças tecnológicas e da complexidade da estrutura.

Componente das empresas orgânicas, extensiva ao comprometimento.

Dispositivo de integração da empresa em face às incertezas do mercado.

A autonomia é limitada pelos diversos tipos de burocracia.

Reservada a uma elite de profissionais para atendimento ao cliente.

A tomada de decisão é decorrente das escolhas estratégicas gerenciais.

Decisão de estratégia gerencial com graus de restrições.

Microação e microprática estratégica dos processos complexos.

\begin{tabular}{|c|c|}
\hline \multicolumn{2}{|c|}{ Empowerment (1990 - ): o aparente poder da autonomia } \\
\hline Conger e Canungo (1988) & Ativação do poder de autoeficácia dos funcionários. \\
\hline Thomas e Velthouse (1990) & Motivação intrínseca da tarefa. \\
\hline Claydon e Doyle (1996) & Ganho de confiança nas relações de trabalho e ética. \\
\hline Honold (1997) & A multidimensionalidade do empowerment. \\
\hline Hardy e Leiba-O'Sullivan (1998) & Poder multifacetado. \\
\hline Smith e Mouly (1998) & Percepção do sentimento de poder. \\
\hline $\begin{array}{l}\text { D'Annunzio-Green e } \\
\text { Macandrew (1999) }\end{array}$ & Transferência do poder. \\
\hline $\begin{array}{l}\text { Herrenkohl, Judson e Heffner } \\
\text { (1999) }\end{array}$ & Revisão do conceito sobre empoderamento. \\
\hline Pearce et al. (2003) & Liderança empoderando o funcionário. \\
\hline Zhang e Bartol (2010) & Liderança empoderando o funcionário e a criatividade. \\
\hline $\begin{array}{l}\text { Maynard, Gilson e Mathieu } \\
\text { (2012) }\end{array}$ & Empoderamento psicológico. \\
\hline Sosik, Chun e Zhu (2014) & $\begin{array}{l}\text { Liderança carismática, o empoderamento psicológico e a identidade moral } \\
\text { do subordinado. }\end{array}$ \\
\hline \multicolumn{2}{|r|}{ Autonomia e pró-atividade } \\
\hline Parker, Williams e Turner (2006) & A autonomia é um importante determinante de resultado pró-ativo. \\
\hline \multicolumn{2}{|r|}{ Autonomia como patrimônio da competência } \\
\hline Zarifian (1999a) & A autonomia como ideal de competência. \\
\hline
\end{tabular}

Fonte: Elaborado pelos autores. 


\section{PROCEDIMENTOS METODOLÓGICOS}

A abordagem da pesquisa foi qualitativa, baseada no construcionismo social, e valeuse da Análise Crítica do Discurso, de Fairclough (2019). Optou-se por um estudo comparativo entre duas empresas de TI que averiguou as convergências e as divergências nas suas práticas.

A seleção das organizações foi baseada na literatura pesquisada e na experiência profissional de um dos pesquisadores nos seus trabalhos de consultoria. Entre 2006 e 2011, as duas empresas de TI em Pernambuco foram clientes de um dos pesquisadores e uma delas foi convidada também para a sua pesquisa de dissertação do mestrado em 2007.

Os critérios de identificação das organizações foram respaldados no referencial teórico, e particularmente na pesquisa de Dellagnelo e Machado-da-Silva (2000) sobre as possíveis evidências de novas formas organizacionais em empresas privadas nos segmentos industriais e de serviços. Dellagnelo e Machado-da-Silva (2000) identificaram que as empresas de tecnologia da informação surgem como indicações de estrutura de ambientes mais flexíveis que podem facilitar práticas de autonomia. Essa identificação também é mencionada pela literatura internacional investigada (ABARESHI; MARTIN; MOLLA, 2011; GUNIA, 2002).

As duas organizações foram investigadas conforme as características contextuais descritas no Quadro 2 que foi elaborado a partir do referencial teórico sobre as NFOs e as NFOT.

Quadro 2 - Tipos de organizações - características contextuais

\begin{tabular}{|c|c|c|}
\hline \multicolumn{3}{|c|}{ TIPOS DE ORGANIZAÇÕES - CARACTERÍSTICAS CONTEXTUAIS } \\
\hline Categorias Analíticas & Burocráticas & Pós-Burocráticas \\
\hline Estrutura & Rígida e centralizada. & Flexível e descentralizada. \\
\hline Controle & Racional. Burocrático. & tralização, autocontrole. \\
\hline Cultura & Mecanicista. & Orgânica (ausência de padronização). \\
\hline Hierarquia & $\begin{array}{l}\text { Existência de uma estrita hierarquia } \\
\text { de autoridade e controle e também } \\
\text { muitas regras. }\end{array}$ & $\begin{array}{l}\text { Existência de menos hierarquia de } \\
\text { autoridade e controle, e também poucas } \\
\text { regras. }\end{array}$ \\
\hline Metas & Eficiência e produtividade. & Aprendizagem. \\
\hline Lide & alizada. & $\begin{array}{l}\text { Horizontalizada e funcionalmente } \\
\text { eclética e participativa. }\end{array}$ \\
\hline Organização do trabalho & $\begin{array}{l}\text { As tarefas são rigidamente } \\
\text { definidas. }\end{array}$ & $\begin{array}{l}\text { As tarefas são ajustadas e redefinidas } \\
\text { mediante o trabalho em equipe. }\end{array}$ \\
\hline & A divisão do trabalho é tradicional. & A divisão do trabalho é flexível e informal. \\
\hline Planejamento estratégico & Responsabilidade dos gestores. & Envolvimento de todos os funcionários. \\
\hline Tomada de decisão & Centralizada nos gestores. & $\begin{array}{l}\text { Participação de todos no processo de } \\
\text { decisão. }\end{array}$ \\
\hline Criatividade & $\begin{array}{l}\text { Pouca ênfase nas competências e } \\
\text { qualificação dos funcionários. }\end{array}$ & $\begin{array}{l}\text { Bastante ênfase nas competências e } \\
\text { qualificação dos funcionários. }\end{array}$ \\
\hline
\end{tabular}

Fonte: Elaborado pelos autores baseados em Clegg (1998); Clegg, Harris e Höpfl (2011); Courpasson (2000a); Dellagnelo e Machado-da-Silva (2000); Escrivão Filho e Guerrini (2010); Everaere (1999b, 2000); Gergen e Tojo (1996) e Gunia (2002).

Foram convidadas três empresas de $\mathrm{TI}$, duas de grande porte e uma de médio porte, pertencentes ao Porto Digital de Pernambuco, pioneiras em serviços de $\mathrm{TI}$, concorrentes entre si e que possuem fama empresarial expressiva na região pelo uso da inovação e da criatividade nos seus processos. Uma empresa de grande porte se recusou a participar da pesquisa alegando que estava em fase de mudança empresarial. Duas empresas aceitaram participar da pesquisa.

Elas foram identificadas como estruturas de médio e grande porte, conforme a classificação do Serviço Brasileiro de Apoio às Micro e Pequenas Empresas (SEBRAE, 2018). As empresas podem ser classificadas em Microempresa (na indústria, até 19 pessoas ocupadas; 
no comércio e serviços, até 09 pessoas ocupadas); Pequena empresa (na indústria, de 20 a 99 pessoas ocupadas; no comércio e serviços, de 10 a 49 pessoas ocupadas); Média empresa (na indústria, de 100 a 499 pessoas ocupadas; no comércio e serviços, de 50 a 99 pessoas ocupadas) e Grande empresa (na indústria, acima de 500 pessoas ocupadas; no comércio e serviços, acima de 100 pessoas ocupadas).

As empresas foram caracterizadas como Empresa de Tecnologia da Informação 1 (ETI1) e Empresa de Tecnologia da Informação 2 (ETI2) para garantir o anonimato.

A ETI1 é uma sociedade anônima de capital nacional fechado. Tem 37 (trinta e sete) anos de atuação no mercado nacional, seu segmento é de serviços de tecnologia da informação. É composta por um diretor-presidente e quatro diretores gerais. O diretorpresidente pertence à família. Tem um quadro de 50 (cinquenta) funcionários, caracterizado como empresa de médio porte. A empresa não possui departamento de gestão de pessoas para o seu próprio funcionário, porém implanta sistema de recursos humanos para os clientes. No período da pesquisa, ela estava em fase de crescimento.

A ETI2 é uma sociedade limitada de capital nacional fechado. Tem 41 (quarenta e um) anos de atuação no mercado nacional, seu segmento é de serviços de tecnologia da informação. É composta por um diretor-presidente e três diretores gerais. Todos pertencem à família. Tem um quadro de 315 (trezentos e quinze) funcionários, caracterizada como empresa de grande porte. A empresa possui departamento de gestão de pessoas para o seu próprio funcionário e de gestão da qualidade. Especificamente, desde outubro/2013, a empresa estava reestruturando a alta gestão e contratando outros diretores, na tentativa de haver uma profissionalização na gestão.

Quanto ao faturamento, as empresas não disponibilizaram com precisão, já que optaram pelo anonimato desse determinado dado na pesquisa.

Segue o quadro 3 para melhor visualização da caracterização das empresas.

Quadro 3-Resumo da caracterização das empresas

\begin{tabular}{|c|c|c|c|c|c|}
\hline EMPRESAS & SEGMENTO & ATUAÇÃO & COMPOSIÇÃO & № FUNC. & PORTE \\
\hline ETI1 & Serviços (privada) & 37 anos & $\begin{array}{c}01 \text { diretor- } \\
\text { presidente + } 04 \\
\text { diretores gerais. }\end{array}$ & 50 & Médio \\
\hline ETI2 & Serviços (privada) & 41 anos & $\begin{array}{l}01 \text { diretor- } \\
\text { presidente + } 03 \\
\text { diretores. }\end{array}$ & 315 & Grande \\
\hline
\end{tabular}

Fonte: Elaborado pelos autores.

$\mathrm{Na}$ primeira empresa, obteve-se uma entrevista com o diretor-presidente que autorizou a realização da pesquisa e ele indicou o diretor administrativo-financeiro para dar o suporte necessário à execução das entrevistas, tais como apresentação do organograma, indicação dos líderes, agendamento de horário, relato dos dados da empresa e a situação econômica, tour pela empresa, seleção da sala de entrevistas, entre outras atividades. $\mathrm{Na}$ segunda empresa, o coordenador da área de qualidade que acumulava a área de gestão de pessoas consentiu a realização da pesquisa e indicou uma analista de recursos humanos para apoiar um dos pesquisadores na realização das entrevistas.

A pesquisa foi composta por vinte entrevistas semiestruturadas, sendo 10 em cada empresa participante. As gerências optaram por cinco líderes formais e estes indicaram os liderados, usando o critério da disponibilidade de tempo para participarem da pesquisa. Os líderes deveriam apresentar vivência mínima de 06 meses em cargos intermediários de liderança e ter vínculo empregatício com a organização por mais de 01 ano. Os liderados também deveriam ter vínculo empregatício com a organização por mais de 01 ano. 
Para melhor identificação da fonte dos dados analisados foi utilizada a seguinte legenda para caracterizar os entrevistados:

1 - Gerência Intermediária (GI): gerência de projetos, desenvolvimento, coordenação, supervisão e analistas com função de liderança.

2 - Pessoal de Base (BA): técnicos, assistentes, programadores e analistas sem função de liderança.

A caracterização dos sujeitos contemplou os dados pessoais dos entrevistados, tais como sexo (feminino ou masculino), idade e escolaridade, e dados profissionais como tempo de empresa e tempo de liderança, conforme Quadro 4.

Quadro 4-Resumo da caracterização dos entrevistados

\begin{tabular}{|c|c|c|c|c|c|c|}
\hline \multicolumn{7}{|c|}{ RESUMO DA CARACTERIZAÇÃO DOS ENTREVISTADOS } \\
\hline & \multicolumn{4}{|c|}{ DADOS PESSOAIS } & \multicolumn{2}{|c|}{ DADOS PROFISSIONAIS } \\
\hline Cargo & $\mathbf{F}$ & M & Idade & Escolaridade & $\begin{array}{l}\text { Tempo de } \\
\text { Empresa }\end{array}$ & $\begin{array}{l}\text { Tempo de } \\
\text { Liderança }\end{array}$ \\
\hline GI & 05 & 05 & \multirow{3}{*}{$\begin{array}{l}\text { Mínima: } 27 \text { anos } \\
\text { Máxima: } 50 \text { anos }\end{array}$} & \multirow[t]{3}{*}{ Mínima: técnico } & \multirow{3}{*}{$\begin{array}{l}\text { Mínima: } 01 \text { ano + } \\
\quad 02 \text { meses } \\
\text { Máxima: } 23 \text { anos }\end{array}$} & \multirow[t]{2}{*}{ Mínima: 06 meses } \\
\hline BA & 05 & 05 & & & & \\
\hline TOTAL & 10 & 10 & & & & Máxima: 09 anos \\
\hline
\end{tabular}

Fonte: Elaborado pelos autores.

Os instrumentos de coleta de informações foram: observação, entrevista semiestruturada e pesquisa documental. Geralmente esses instrumentos são utilizados quando a pesquisa é orientada para o estudo de casos (BRYMAN, 2004; MERRIAM, 2009). A coleta dos dados foi iniciada e finalizada no mês de outubro de 2013.

A observação qualitativa implicou em avaliar o local ou o terreno da pesquisa realizando registros necessários para a primeira compreensão do fenômeno. A grade de observação traduziu-se no olhar sobre o local que incluiu a decoração, os materiais presentes, as cores, os papéis do local de trabalho, os móveis, a disposição das mesas e cadeiras, recepção, barulhos, e na escuta das pessoas, comportamentos, interações, linguagem nas duas empresas de $\mathrm{TI}$.

A entrevista semiestruturada foi composta por perguntas abertas contemplando os vinte e seis eixos temáticos elencados abaixo.

De acordo com o referencial teórico, identificaram-se vinte e seis eixos temáticos que perpassam as NFOT, a liderança e a autonomia, e após serem catalogados auxiliaram na elaboração das perguntas da entrevista semiestruturada antes do início da coleta. São eles: 1.autonomia, 2.autoridade, 3.avaliação, 4.competência, 5.comunicação, 6.confiança, 7.coordenação das atividades, 8.controle, 9.criatividade, 10.delegação, 11.democracia, 12.disciplina, 13.ensino-aprendizagem e orientação, 14.hierarquia, 15.influência, 16.iniciativa, 17.inovação, 18.liderança, 19.participação em equipe, 20.poder, 21.reconhecimento, 22.regulação do trabalho, 23.relações interpessoais, 24.respeito, 25.responsabilidade e 26.tomada de decisão.

Os vinte e seis eixos temáticos foram reunidos em nove categorias devido às afinidades conceituais e determinaram as bases de análise dos dados. Algumas categorias absorveram mais de um eixo temático e uma foi agrupada (avaliação e reconhecimento). Entende-se que a forma como o indivíduo se auto avalia e é avaliado por outro tem como consequência o seu reconhecimento profissional. Ressalta-se que a categoria é definida como um "conjunto de análises dispostas de significações próximas, de características formais ou de propriedades 
similares, como por exemplo, velho é sinônimo de ancião ou conotações equivalentes como poder e riqueza" (GIORDANO, 2003, p. 293).

As nove categorias de análises foram: 1 . Avaliação e reconhecimento; 2. Comunicação (influência); 3. Construção relacional (relações interpessoais, confiança e respeito); 4. Controle (disciplina e regulação do trabalho); 5. Ensino-aprendizagem e orientação (competência, inovação e criatividade); 6. Hierarquia; 7. Participação em equipe (responsabilidade e iniciativa); 8. Poder (autoridade, coordenação das atividades e democracia); 9. Tomada de decisão (delegação). Essas nove categorias estão associadas entre si, sem limites entre elas.

Inicialmente, foram entrevistados os líderes e logo em seguida os liderados, conforme o tempo disponível de cada um no trabalho. Primeiro, levantaram-se os dados sociodemográficos dos participantes por meio de um formulário (data de nascimento, idade, gênero, profissão, estado civil, escolaridade, endereço pessoal e/ou da empresa, formas gerais de contato) e os dados profissionais (departamento, setor, cargo atual, tempo de empresa, tempo no cargo de liderança, número de subordinados diretos, indiretos e terceirizados, promoção na empresa, treinamentos realizados e outras atividades profissionais exercidas fora da empresa). Após, foram realizadas as perguntas abertas sobre os vinte e seis eixos temáticos da pesquisa. Em média, as entrevistas dos líderes duraram em torno de uma hora e meia até duas horas, e a dos liderados, em torno de uma hora até uma hora e meia. Todas as entrevistas foram individuais e ocorreram na sala de reunião de cada empresa devidamente silenciosa, reservada e confortável, proporcionando um ambiente de confidencialidade. Os entrevistados autorizaram a gravação e a transcrição das entrevistas. Cada transcrição durou em média de duas a três horas de trabalho.

Na pesquisa documental, o diretor da ETI1 disponibilizou um material elaborado por ele que foi distribuído para todos os funcionários da empresa em anos anteriores, ainda repassado no presente, ilustrado por meio de charges, e indicou a homepage da empresa. A ETI2 enviou um e-mail e sugeriu também a homepage da empresa. Durante a permanência na ETI2, um dos pesquisadores observou os quadros de avisos elaborados pela área de gestão de pessoas. A indicação da homepage sugere uma diminuição do material impresso nas duas empresas. Todos os documentos colhidos e sugeridos, incluindo os organogramas, foram analisados.

Os dados qualitativos foram tratados pela análise crítica do discurso (ACD) de Fairclough (2019) por meio de um modelo tridimensional: 1) a análise textual averiguou aspectos, tais como vocabulário, gramática, coesão, estrutura textual, polidez, humor/ironia, transitividade e ethos (hábitos, costumes e valores que constroem o eu); 2 ) a análise da prática discursiva referiu-se a produção, distribuição e consumo do texto, coerência, intertextualidade manifesta e interdiscursividade; 3) a análise da prática social revelou os aspectos ideológicos (modalidades de poder), tais como ordens de discurso, sentidos das palavras, pressuposições, metáforas, provérbios e estilo, e os hegemônicos (domínio de uma classe dominante), tais como relações sociais, efeitos ideológicos e políticos do discurso, e orientações políticas, culturais e sociais.

As três análises estão interrelacionadas entre si, não existe uma delimitação nítida entre elas, de forma que contemplam tanto a forma como o conteúdo para dialogarem entre si no intuito de que se compreendam as relações sociais existentes. Também, optou-se por dialogar com outras perspectivas teóricas, tais como Bakhtin (2012), Levinson (2007) e Pêcheux (2016) para complementar a análise sob o prisma da triangulação teórica. 
Os procedimentos que asseguram a credibilidade de uma pesquisa qualitativa devem esclarecer a construção social do conhecimento. Para isto, adotou-se o esquema de múltiplas vozes (triangulação dos dados), discussão em pares, checagem dos informantes (validação comunicativa) e surpresa (sentido de descoberta sobre o tema) (CRESWELL, 2010; FLICK, 2013; PAIVA JÚNIOR; LEÃO; MELLO, 2011).

\section{ANÁLISE DOS RESULTADOS}

Cada categoria foi analisada individualmente de forma que possibilitou o entendimento discursivo, envolvendo as relações de poder, a produção de sentidos e significados sobre liderança e autonomia, processos ideológicos e hegemônicos.

Os quadros 5 (ETI1) e 6 (ETI2) apresentam a matriz discursiva da análise crítica das nove categorias de cada empresa, especificando os exemplos de alguns fragmentos discursivos e a construção analítica do discurso. Ressalta-se que a análise completa possui outros fragmentos que não foram apresentados por serem extensos e que os fragmentos foram preservados como foram pronunciados por seus entrevistados, sem lapidação da norma culta.

Posteriormente, iniciam-se os comentários sobre os resultados, tecendo uma discussão sobre a relação entre as nove categorias com base nos componentes norteadores da ACD.

Quadro 5 - Matriz discursiva da análise crítica - ETI1

\begin{tabular}{|c|c|c|}
\hline \multicolumn{3}{|c|}{ ETI1 } \\
\hline Categorias & Fragmentos discursivos - exemplos & Construção analítica do discurso \\
\hline 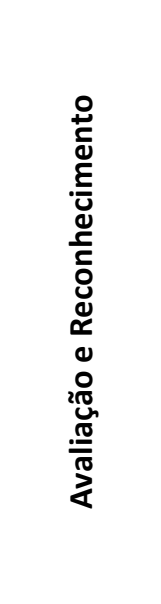 & $\begin{array}{l}\text { “Nas outras empresas que eu trabalhava, } \\
\text { tinha bastante amarrado isso aí, a partir } \\
\text { do momento que eu sentava na minha } \\
\text { cadeirinha, já tinha um reloginho lá, com } \\
\text { a hora que você está fazendo, } \\
\text { geralmente as listagens são definidas por } \\
\text { prazos (....) aí conseguia avaliar bastante } \\
\text { isso aí. Talvez lá, não precisasse nem } \\
\text { fazer avaliação de desempenho, o } \\
\text { próprio quadro é um soft que a gente } \\
\text { usava e já mostrava ali toda a } \\
\text { produtividade de cada um, aqui não tem } \\
\text { isso, por ser bastante flexível, peca" } \\
\text { (BA3). }\end{array}$ & $\begin{array}{l}\text { Componentes norteadores encontrados: } \\
\text { Lexicalização, } \\
\text { Intertextualidade manifesta, Humor/Ironia, } \\
\text { Polidez, Pressuposição, Ordem de discurso. } \\
\text { Análise crítica: } \\
\text { - Domínio ideológico sagrado (verbo 'pecar'). } \\
\text { - Controle ideológico por meio dos jogos de } \\
\text { dominação e submissão, e dos polos de atividade } \\
\text { e passividade (ironia: "cadeirinha" e "reloginho", } \\
\text { "soft"). } \\
\text { - Processo de autoempoderamento (“Nas outras } \\
\text { empresas", "aqui", "por ser bastante flexível”, } \\
\text { "peca" - BA3 avalia e julga o processo). }\end{array}$ \\
\hline 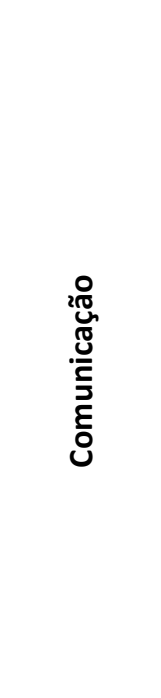 & $\begin{array}{l}\text { “A comunicação já pelo outro lado é bem } \\
\text { tranquila, é bem, acontece de uma forma } \\
\text { bem fácil, posso lhe dizer. É você, têm } \\
\text { vários setores hoje, (...) na empresa, que } \\
\text { o funcionário consegue conversar com } \\
\text { todos esses setores. Sem uma } \\
\text { burocracia, sem um empecilho, é, você } \\
\text { consegue também se for do caso de } \\
\text { alguém ter um problema tem meios de se } \\
\text { comunicar com as pessoas, mesmo que } \\
\text { não estejam presentes, então isso tudo é } \\
\text { bastante favorável” (BA4). }\end{array}$ & $\begin{array}{l}\text { Componentes norteadores encontrados: } \\
\text { Pressuposição, Interdiscursividade, Estilo, } \\
\text { Lexicalização, Neologismo. } \\
\text { Análise crítica: } \\
\text { - Relações heterárquicas ("pelo outro lado" - } \\
\text { significa o líder, "mesmo que não estejam } \\
\text { presentes"). } \\
\text { - Diminuição dos controles: discurso do } \\
\text { antiburocrático ("você", "que”, "consegue } \\
\text { conversar"). } \\
\text { - Controles invisíveis da burocracia, remodelados } \\
\text { pela flexibilidade e fluidez das ações ("sem } \\
\text { burocracia”, "sem um empecilho"). } \\
\text { - Discursos ideológicos e de manutenção do poder } \\
\text { ("alguém”, "é bastante favorável”). }\end{array}$ \\
\hline
\end{tabular}




\begin{tabular}{|c|c|c|}
\hline 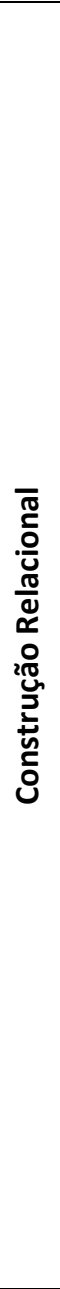 & $\begin{array}{l}\text { “Eles têm muita confiança, eu acho que a } \\
\text { empresa tem mais confiança no } \\
\text { funcionário do que o funcionário na } \\
\text { empresa, porque era uma coisa que eu } \\
\text { reclamava muito, por exemplo, } \\
\text { antigamente a gente fazia hora extra e a } \\
\text { gente mesmo fazia o controle, e eu nunca } \\
\text { gostei disso e eu ía pro meu diretor e } \\
\underline{\text { reclamava, menino, como é que eu }} \\
\underline{\text { mesmo estou fazendo hora extra e se eu }} \\
\underline{\text { quiser botar dez, quinze horas aqui e aí? }} \\
\text { (...) É eu acho que a empresa confia mais } \\
\text { no funcionário,(...) a empresa deveria ter } \\
\underline{\text { um certo controle do que o funcionário }} \\
\underline{\text { na empresa" (GI2). }} \\
\text { “todos nós somos amigos, todos nós } \\
\underline{\text { brincamos não só entre os líderes, mas }} \\
\text { também os da minha equipe e até } \\
\text { mesmo nos outros setores, a interação é } \\
\text { muito boa” (BA4). }\end{array}$ & 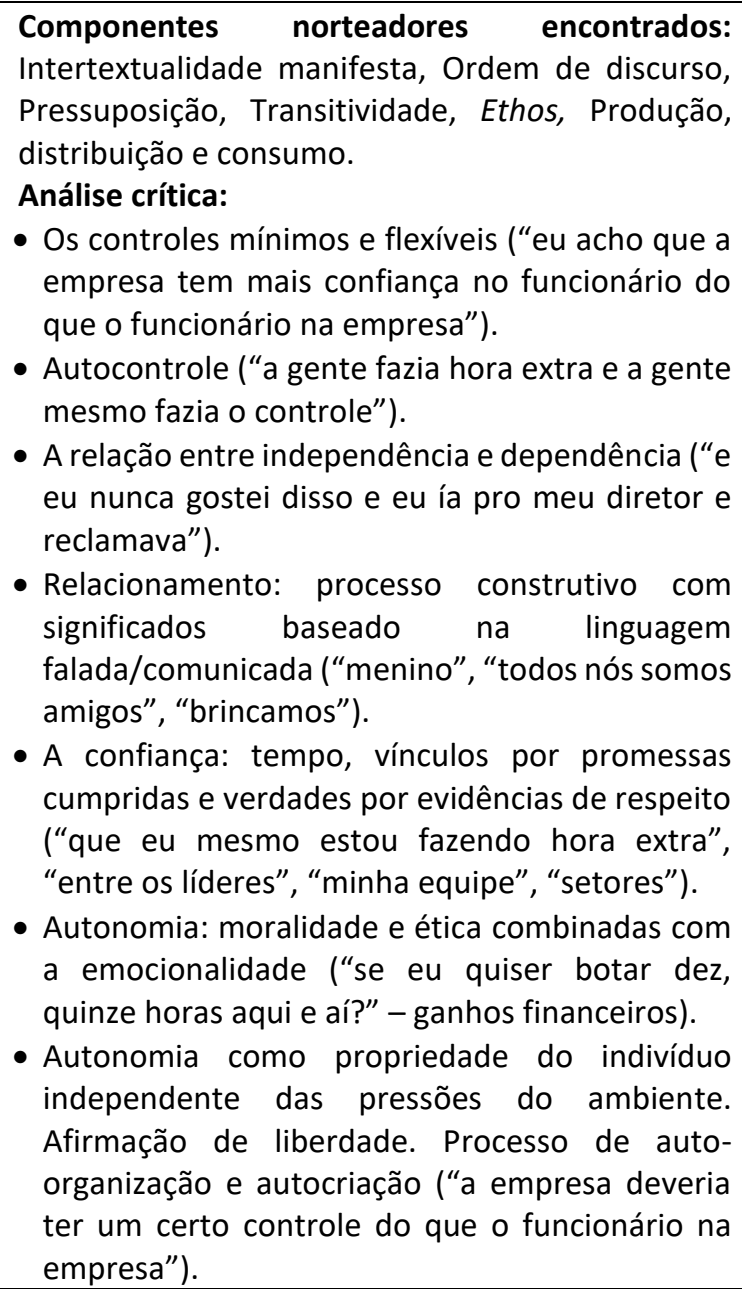 \\
\hline 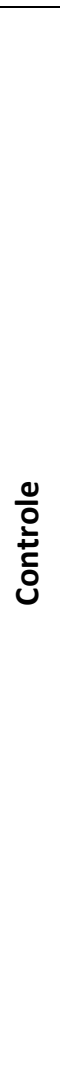 & $\begin{array}{l}\text { “É flexível demais, no meu ver sim, } \\
\underline{\text { deveria ter uma determinação do tempo. }} \\
\text { [Determinação?] (...) por que a gente } \\
\text { atende a terceiros, então isso aí gera uma } \\
\text { expectativa, de quem tá do outro lado, } \\
\text { aguardando você resolver um problema. } \\
\text { Então isso você gera aquela expectativa } \\
\text { (baixa muito o tom de voz), eu atendi } \\
\text { você hoje, mas não vou esperar que você } \\
\text { resolva com um mês e quinze dias, por } \\
\text { que você também percebe se o grau do } \\
\text { problema que você está passando pra } \\
\text { mim, se vai ser demorado ou não" (G12). } \\
\text { “Eu acho que pelo menos a única coisa } \\
\text { que eles exigem é que você pelo menos } \\
\underline{\text { comunique, isso eles ficam muito putos, }} \\
\text { [palavra de baixo calão, pronunciada } \\
\text { como uma compreensão do sentimento] } \\
\text { quando você não comunica" (BA1). }\end{array}$ & 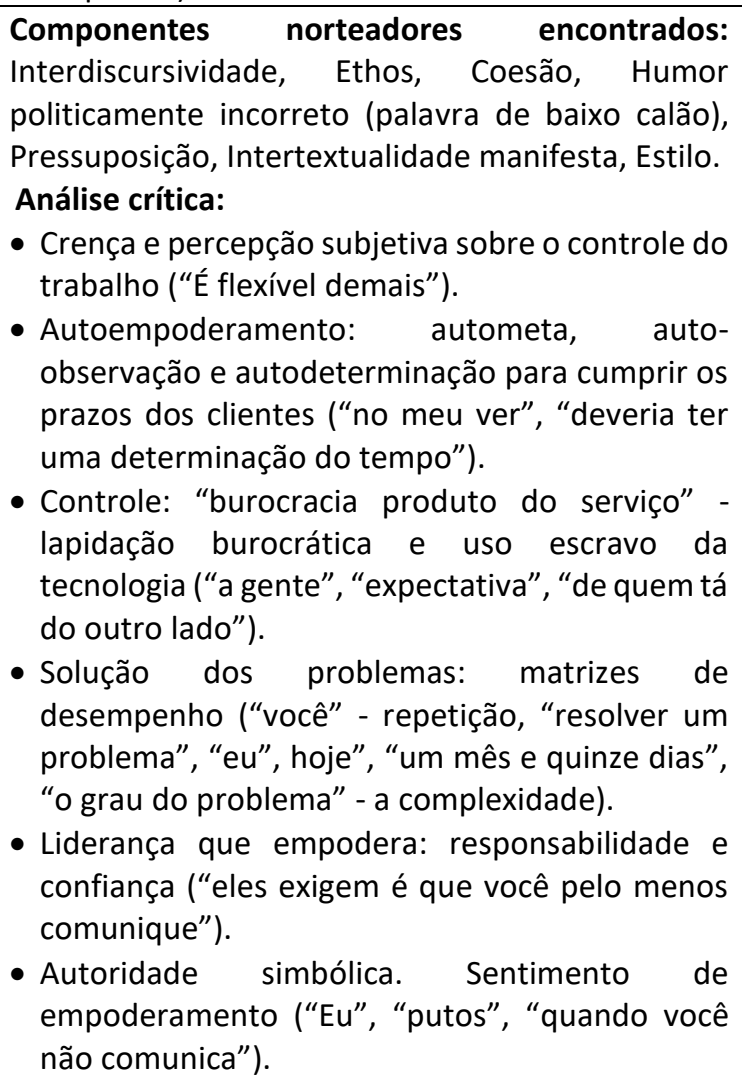 \\
\hline
\end{tabular}




\begin{tabular}{|c|c|c|}
\hline 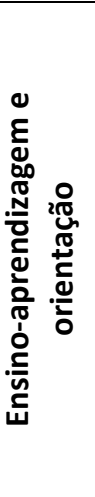 & $\begin{array}{l}\text { "É informal (...) em questão do } \\
\text { conhecimento, dos mais experientes aos } \\
\underline{\text { mais novos. Ninguém aqui, eu não vejo }} \\
\underline{\text { nenhum que detenha conhecimento a }} \\
\underline{\text { benefício próprio. Mas falta aqui essa }} \\
\underline{\text { formalização dessa transferência de }} \\
\text { procedimentos no momento adequado } \\
\text { pra isso" (GI3). }\end{array}$ & $\begin{array}{l}\text { Componentes norteadores encontrados: } \\
\text { Interdiscursividade, Estrutura textual. } \\
\text { Análise crítica: } \\
\text { - A ideia de expertise ou métier aponta para } \\
\text { processos de autonomia ("conhecimento, dos } \\
\text { mais experientes aos mais novos"). } \\
\text { - Inovação e criatividade: estratégia de } \\
\text { manutenção da empresa ("eu não vejo nenhum } \\
\text { que detenha conhecimento a benefício } \\
\text { próprio", "falta", "formalização"). }\end{array}$ \\
\hline 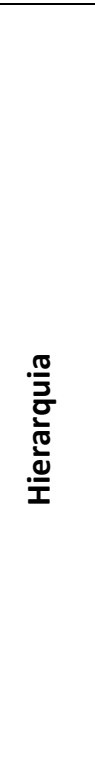 & 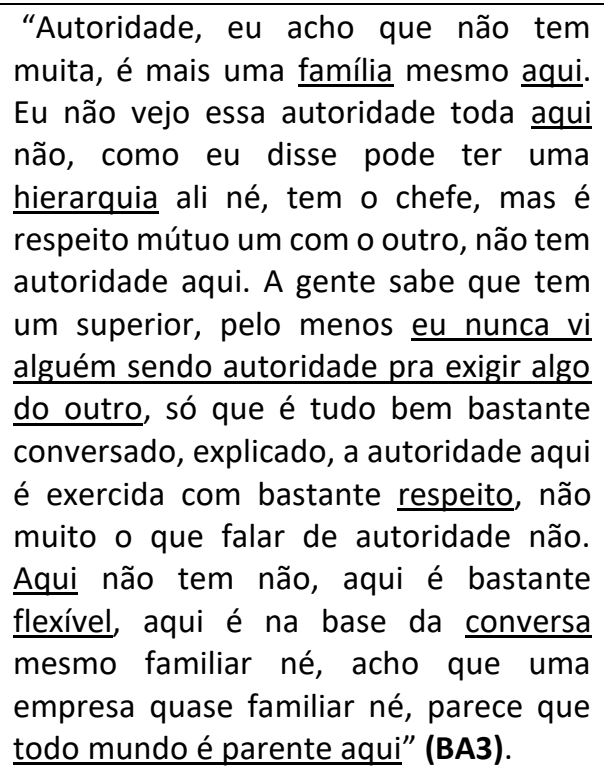 & $\begin{array}{l}\text { Componentes norteadores encontrados: } \\
\text { Metáfora, Interdiscursividade, Intertextualidade } \\
\text { manifesta. } \\
\text { Análise crítica: } \\
\text { - Controles burocráticos antigos combinados } \\
\text { com os novos controles das novas formas de } \\
\text { organização do trabalho ("família" como } \\
\text { metáfora, "aqui" - repetição, "hierarquia", "eu } \\
\text { nunca vi alguém sendo autoridade pra exigir } \\
\text { algo do outro"). } \\
\text { - Processo evolucionário da burocracia - o velho } \\
\text { e o novo podem coexistir na mesma } \\
\text { organização ("respeito", "aqui", "flexível", } \\
\text { "conversa", "todo mundo é parente aqui" - } \\
\text { reforço da metáfora"). }\end{array}$ \\
\hline 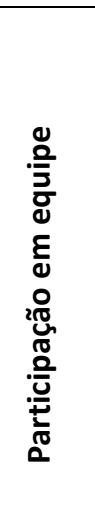 & $\begin{array}{l}\text { “(...), o processo de equipe são unidos, } \\
\text { cada um tem o seu projeto, mas na hora } \\
\text { de você botar aquele projeto pra andar, } \\
\text { todo mundo vai junto, embora que você } \\
\frac{\text { não vá participar daquele projeto, mas }}{\text { você tem que ter consciência do que tá }} \\
\frac{\text { sendo feito, pra você também não ficar }}{\text { de fora, então junta todo mundo (...) }} \\
\text { debate todo mundo dá a sua opinião, } \\
\text { mas todo mundo está ciente do que vai } \\
\text { ser feito e de como vai ser feito" (GI2). }\end{array}$ & $\begin{array}{l}\text { Componentes norteadores encontrados: } \\
\text { Interdiscursividade, Polidez. } \\
\text { Análise crítica: } \\
\text { - Uso das competências dos funcionários (“cada } \\
\text { um tem o seu projeto"). } \\
\text { - Relações heterárquicas: uso da participação } \\
\text { (“todo mundo vai junto, embora que você não } \\
\text { vá participar daquele projeto, mas você tem } \\
\text { que ter consciência do que tá sendo feito, pra } \\
\text { você também não ficar de fora”). }\end{array}$ \\
\hline
\end{tabular}




\begin{tabular}{|c|c|c|}
\hline $\begin{array}{l}\frac{1}{0} \\
\frac{0}{0}\end{array}$ & $\begin{array}{l}\text { [Fala do diretor-presidente] “(...) ele é } \\
\text { um homem muito carismático, ele brinca } \\
\text { com a gente de vez em quando, mas ele } \\
\text { é dominador" (BA2). } \\
\text { “(...) A empresa é tipo uma hierarquia a } \\
\text { gente aqui é bem mais aberto. Com } \\
\text { relação do superior com o subordinado } \\
\text { eu não vejo [pequeno silêncio], é } \\
\text { ninguém se impondo nada não, [fala o } \\
\text { nome do diretor-presidente], mas ele } \\
\text { não tem assim, assim o é jogo muito } \\
\text { aberto, muita conversa e não tem essas } \\
\underline{\text { coisas de superior não, eu tava vendo }} \\
\text { hoje as conversas do pessoal, ninguém } \\
\text { tenta empurrar, pisar ou não, se eu sou } \\
\text { superior e você tem que me obedecer, e } \\
\text { sempre são conversas amigáveis” (BA2). }\end{array}$ & $\begin{array}{l}\text { Componentes norteadores encontrados: Estilo } \\
\text { Intertextualidade manifesta, Interdiscursividade, } \\
\text { Ordem de discurso, Força do enunciado. } \\
\text { Análise crítica: } \\
\text { - Liderança carismática ("carismático"). } \\
\text { - Uso do poder legítimo (cargo) e do poder da } \\
\text { identificação (carisma) que legitimam a } \\
\text { autoridade e a centralização ("hierarquia”, "é } \\
\text { ninguém se impondo nada não", "não tem essas } \\
\text { coisas de superior não"). } \\
\text { - Coordenação das atividades: jogos explícitos e } \\
\text { jogos implícitos ("jogo muito aberto", } \\
\text { "carismático", "dominador"). } \\
\text { - Autoridade carismática: laços afetivos e líder } \\
\text { com função de proteção dos seus seguidores } \\
\text { ("ninguém tenta empurrar, pisar ou não"). } \\
\text { - Autonomia: estratégia organizacional em } \\
\text { determinadas situações como prática } \\
\text { democrática ("conversas amigáveis"). }\end{array}$ \\
\hline 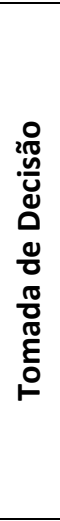 & $\begin{array}{l}\text { “Bombeiro. Apagar o fogo se está com } \\
\text { um problema usa muito o status de } \\
\text { bombeiro, se está com um problema no } \\
\text { cliente, então tem que ser resolvido aí a } \\
\text { delegação é isso aí, (...), vai chegar é } \\
\text { mandar uma pessoa pra assumir } \\
\text { entendeu? Aí esse fato de delegar essas } \\
\text { tarefas é meio como apagar incêndio" } \\
\text { (BA1). }\end{array}$ & $\begin{array}{l}\text { Componentes norteadores encontrados: } \\
\text { Metáfora, Interdiscursividade } \\
\text { Análise crítica: } \\
\text { - Competências: favorece a autonomia e a mais- } \\
\text { valia do trabalho ("bombeiro" como metáfora, } \\
\text { "status de bombeiro" como um ornamento } \\
\text { brilhante e de excelência no trabalho). } \\
\text { - Decisões: envolvem microações e macroações } \\
\text { estratégicas ("um problema no cliente", } \\
\text { "delegação"). } \\
\text { - As não decisões apresentam um foco político } \\
\text { ("apagar incêndio"). }\end{array}$ \\
\hline
\end{tabular}

Fonte: Elaborado pelos autores.

A análise das nove categorias permitiu identificar que estruturalmente, a ETI1 investe no domínio ideológico que evoca o caráter do sagrado e da proteção dos funcionários (PAGÈS et al., 2008). Os controles são burocráticos invisíveis modelados pela flexibilidade. A empresa combina práticas tradicionais de gestão com práticas novas, de forma que se evidencia o processo evolucionário da burocracia (PALMER; BENVENISTE; DUNFORD, 2007). As NFOT estão presentes na complexidade das tarefas, na resolução dos problemas e nas altas demandas de responsabilidade que institui o discurso antiburocrático (CLEGG; HARRIS; HÖPFL, 2011; COURPASSON, 2000a, 2000b).

Quanto à liderança, as relações estabelecidas são heterárquicas com um mínimo de hierarquia, envolvendo o diálogo constante de negociação, renegociação e consenso (GRAETZ; SMITH, 2009; GRONN, 2000; HOSKING; DACHLER, 1995; HOSKING, 2006). Trata-se da liderança que empodera (empowering leadership), atuando diretamente sobre as necessidades de autonomia e liberdade dos indivíduos (D'INTINO et al., 2007; MANZ, 1986; MANZ; SIMS, 1980), envolvendo a responsabilidade (MÜLLER et al., 2013; YUN; COX; SIMS, 2006) e a confiança (DIRKS; FERRIN, 2001; LANGFRED, 2004; ROTTER, 1980). Existe uma crença e percepção subjetiva sobre o controle do trabalho que leva ao sentimento de autoempoderamento (EVANS; FISCHER, 1992; MALIK, 2012; MAYNARD; GILSON; MATHIEU, 2012; SMITH; MOULY, 1998), onde o indivíduo vivencia a autometa, a auto-observação e a autodeterminação (DECl; RYAN, 2004; GAGNÉ; DECl, 2005). 
Ressalta-se que surge também a liderança carismática (WEBER, 2008) associada ao poder legítimo e ao poder de identificação referente ao dono (FRENCH; RAVEN, 1965). O carisma é uma qualidade de uma personalidade individual caracterizada como um dom divino, sobrenatural e de poderes excepcionais, não acessíveis a todas as pessoas. O portador do carisma é detentor de qualidades excepcionais na percepção dos seguidores (WEBER, 2008). Desta forma, geralmente, quanto mais alta a posição, mais alto tende a ser o poder legítimo. Um líder com alto poder legítimo induz ao consentimento ou influencia os outros, porque eles sentem que o líder tem o direito, conforme sua posição na organização, de desejar e esperar que suas sugestões sejam aceitas e seguidas. O poder legítimo abriga a coerção e as recompensas no desempenho de suas atividades. E o poder de identificação é baseado nos traços pessoais do líder pela admiração e apreciação de sua personalidade, estando associada ao carisma (FRENCH; RAVEN, 1965).

Em relação às abordagens contemporâneas da liderança e à distribuição do poder evidencia-se a abordagem relacional (HOSKING; DACHLER, 1995; UHL-BIEN, 2006). Observase a presença do empoderamento, onde a autoridade e a responsabilidade surgem da dinâmica relacional. A autonomia acontece naturalmente decorrente dos traços da liderança principal e se estica para as outras lideranças e os liderados, conforme a situação e o contexto (SPILLANE; HALVERSON; DIAMOND, 2001). O poder é distribuído de acordo com a experiência, o conhecimento e as competências dos funcionários.

A autonomia pertence ao indivíduo independente das pressões do ambiente (FLEIG, 2007; LIMA, 2004). É uma afirmação de liberdade (TERSSAC, 2012) e um processo de autoorganização e autocriação (VARELA, 1989). Na ETI1, a autonomia conserva os princípios éticos combinados com a emocionalidade e a afetividade (CAYGILL, 2000). A autonomia e o controle são faces de um equilíbrio de forças (REYNAUD, 1988), de modo que, permitem a comunhão da identidade profissional e social (SAINSAULIEU, 1977) sem implicar no adoecimento. Evidencia-se um processo de antisubmissão e antireverência advindo da postura da alta cúpula que autoriza indiretamente ao funcionário os atos de rebeldia e favorece a regulação das tensões. A autonomia também é utilizada como estratégia organizacional (EVERAERE, 1999a; TERSSAC, 1999; ZARIFIAN, 1999b), por meio de práticas democráticas.

Em síntese, a análise dos dados permite afirmar que existe a vivência e a experiência de autonomia no trabalho na ETI1, equilibrando o individual e o coletivo. A autonomia não está isenta dos conflitos e das tensões no ambiente de trabalho, e apesar de existirem choques com os procedimentos, as políticas da estrutura e as relações de poder, ela se realiza e acontece. O líder principal por meio da sua personalidade impõe uma estrutura de NFOT que permite o engajamento de poder e a vivência da autonomia na prática.

A seguir apresenta-se o Quadro 6 da matriz discursiva da ETI2. 
Quadro 6 - Matriz discursiva da análise crítica - ETI2

\begin{tabular}{|c|c|c|}
\hline \multicolumn{3}{|c|}{ ETI2 } \\
\hline Categorias & Fragmentos discursivos - exemplos & Construção analítica do discurso \\
\hline 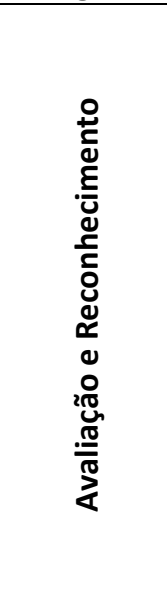 & $\begin{array}{l}\text { “(...) persegue e até demite, então isso } \\
\text { acontece bastante, eu que já to aqui há } \\
\text { muito tempo (...)” (GI1). } \\
\text { “(...) não é um falando com o outro e sim, } \\
\text { um sistema que você vai lá e responde } \\
\frac{\text { algumas perguntas e pode fazer }}{\text { observações e no final vem uma psicóloga }} \\
\text { e passa o resultado para você” (GI4). }\end{array}$ & $\begin{array}{l}\text { Componentes norteadores encontrados: Coesão, } \\
\text { Estilo, Produção, distribuição e consumo } \\
\text { Coerência, Intertextualidade manifesta, Força do } \\
\text { enunciado. } \\
\text { Análise crítica: } \\
\text { - Taylorismo tradicional na organização do } \\
\text { trabalho ("persegue e até demite”). } \\
\text { - "Mix de controle": Recursos humanos e a } \\
\text { tecnologia para a avaliação dos resultados e do } \\
\text { comportamento do indivíduo tanto estrutural- } \\
\text { normativo quanto simbólico (“sistema”). } \\
\text { - Jogos de poder por controles implícitos e } \\
\text { explícitos ("responde algumas perguntas e pode } \\
\text { fazer observações"). }\end{array}$ \\
\hline 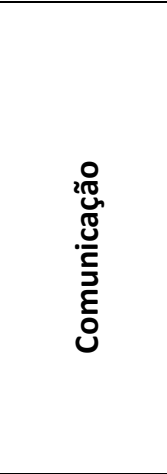 & $\begin{array}{l}\text { “A comunicação é boa a gente tem um } \\
\text { Fala Empresa [citação do nome da } \\
\text { empresa], a gente tem um portal da } \\
\text { comunicação, então assim a gente tem } \\
\text { muitos instrumentos, a gente tem uma } \\
\text { intranet com procedimentos, a gente tem } \\
\text { várias é, várias de comunicação de } \\
\text { informações, e-mail, dentre outras" (GI1). } \\
\text { “eu não sei hoje o que é que as outras } \\
\text { equipes fazem (...)" (GI3). }\end{array}$ & $\begin{array}{l}\text { Componentes norteadores encontrados: } \\
\text { Produção, distribuição e consumo, Estilo, } \\
\text { Pressuposição, Estrutura textual, Polidez, } \\
\text { Neologismo. } \\
\text { Análise crítica: } \\
\text { - Controles burocráticos por meio da tecnologia } \\
\text { ("Fala Empresa", "um portal da comunicação", } \\
\text { "intranet", "e-mail”). } \\
\text { - Isolamento físico das equipes: fragilização da } \\
\text { identidade psicossocial dos indivíduos ("eu não } \\
\text { sei hoje o que é que as outras equipes fazem"). }\end{array}$ \\
\hline 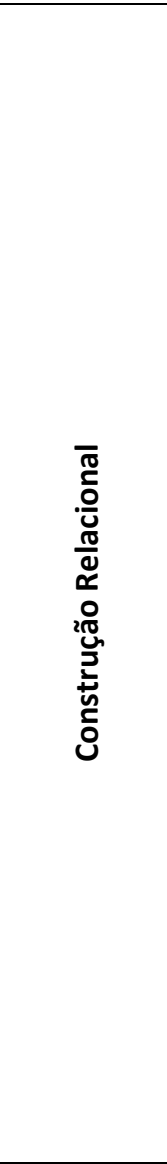 & 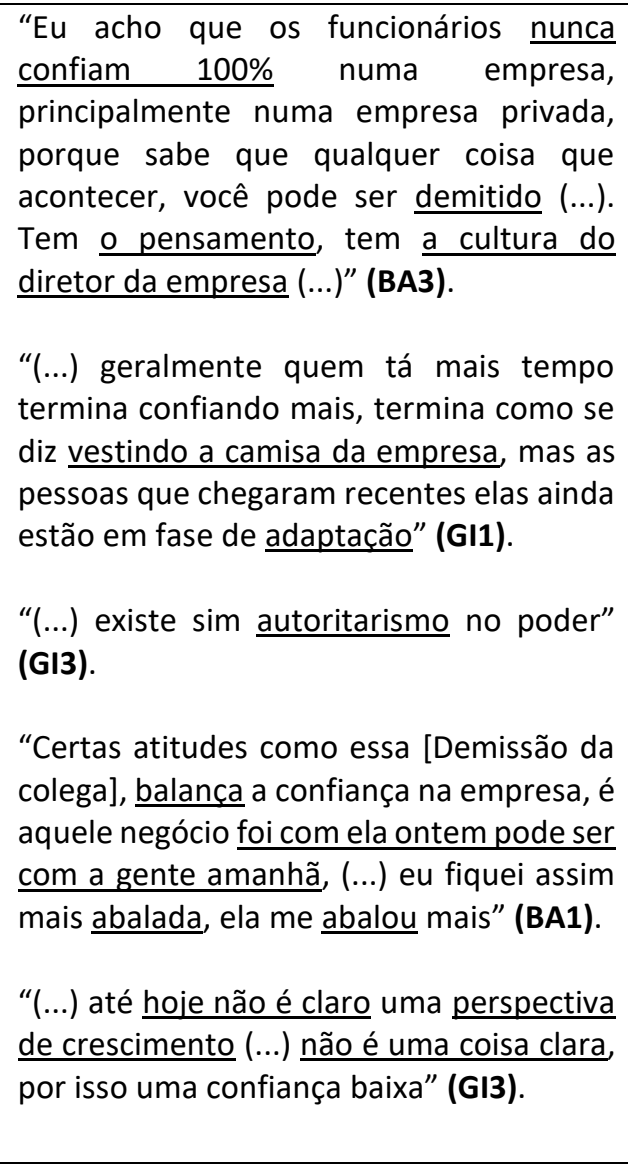 & 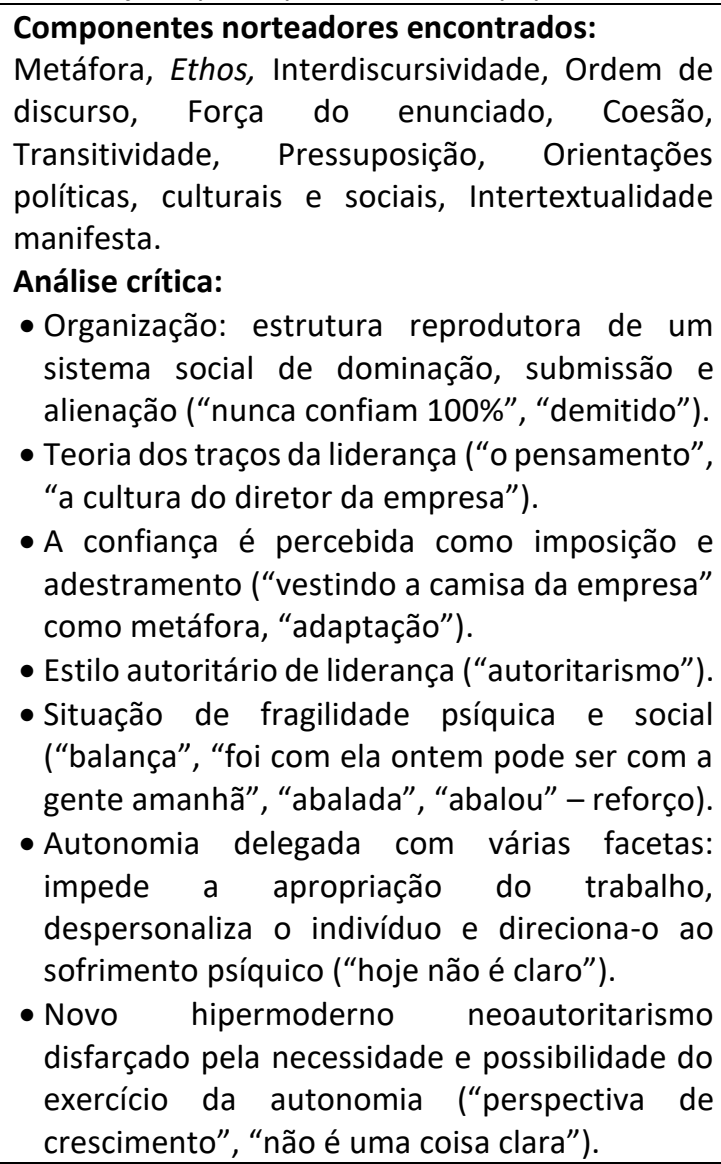 \\
\hline
\end{tabular}




\begin{tabular}{|c|c|c|}
\hline & 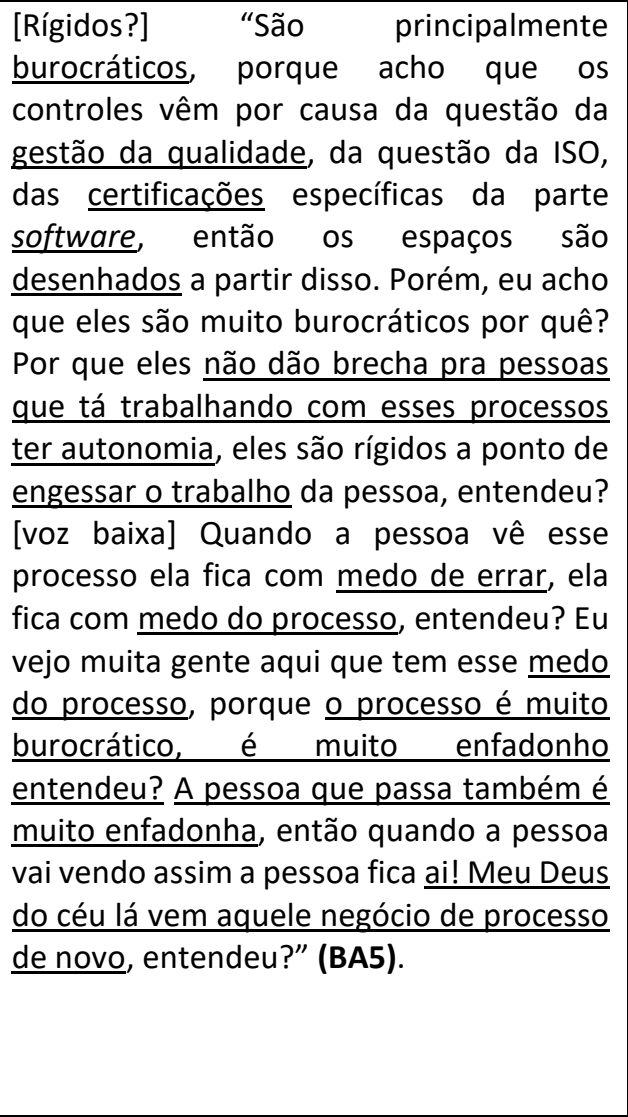 & 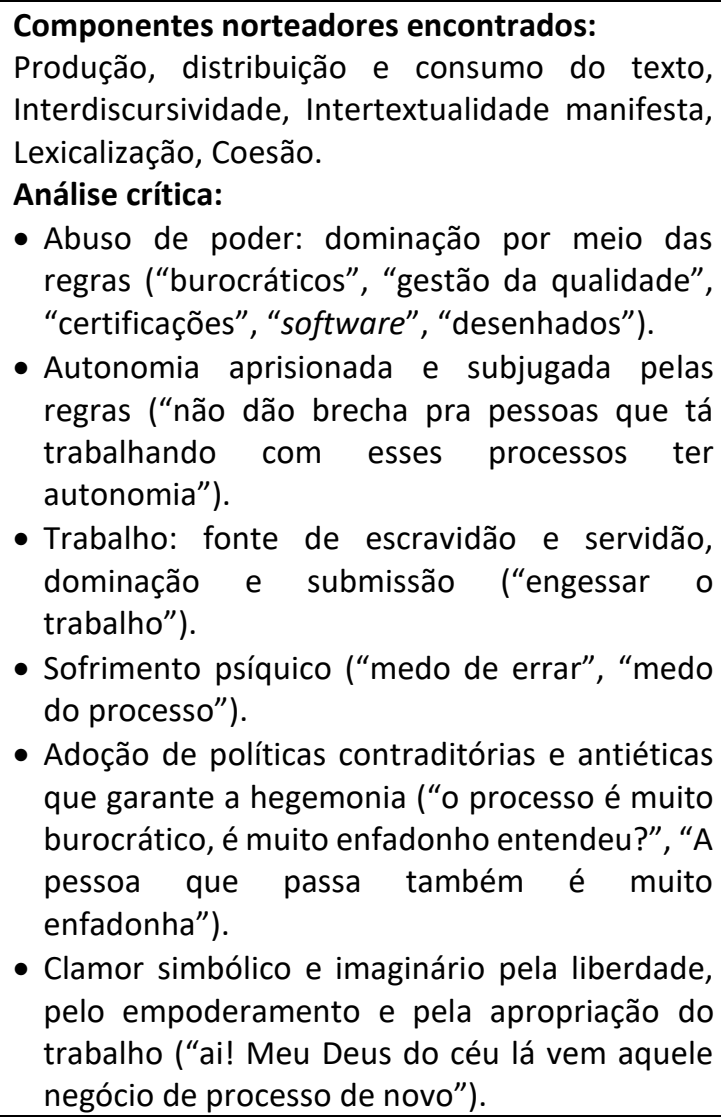 \\
\hline 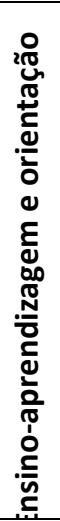 & $\begin{array}{l}\text { “(...) eles fazem uma lista enorme de } \\
\text { cursos que eu deveria fazer (...), aí faz } \\
\text { aquela ilusão aí vai provas juntas né eu sei } \\
\text { que falta verbas pra todo mundo fazer } \\
\text { cursos. Mas às vezes, eles falam tanto e } \\
\text { não fazem, até fica você tem que ser bom } \\
\text { naquilo (...)” (BA3). } \\
\text { “(...) a gente não consegue dar realmente } \\
\underline{\text { ideias, as pessoas até brincam com as }} \\
\text { ideias, porque eles sabem que as ideias } \\
\text { delas não vão ser consideradas" (GI5). }\end{array}$ & $\begin{array}{l}\text { Componentes norteadores encontrados: } \\
\text { Lexicalização, Intertextualidade manifesta. } \\
\text { Análise crítica: } \\
\text { - Adestramento das pessoas por meio de } \\
\text { treinamentos ("eles fazem uma lista enorme } \\
\text { de cursos que eu deveria fazer"). } \\
\text { - Imaginário enganador ("ilusão", "eles falam } \\
\text { tanto e não fazem"). } \\
\text { - A autonomia é utilizada como uma manobra } \\
\text { do poder ("a gente não consegue dar } \\
\text { realmente ideias", "brincam”, "as ideias delas } \\
\text { não vão ser consideradas"). }\end{array}$ \\
\hline 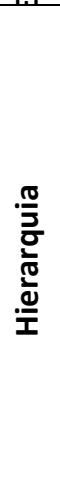 & $\begin{array}{l}\text { “Confusa, muito confusa, porque a gente } \\
\text { tem pessoas que não tem a menor } \\
\text { capacidade de exercer hierarquia } \\
\text { nenhuma sobre algumas outras as pessoas } \\
\text { aqui, talvez porque a empresa tenha sido } \\
\text { até hoje muito familiar, parece que tá } \\
\text { mudando. Mas acho que têm algumas } \\
\text { pessoas que não se posicionam a ponto de } \\
\text { exercer um cargo de hierarquia. } \\
\text { Comportamentalmente, mentalmente e } \\
\text { tecnicamente (...)" (GI5). }\end{array}$ & $\begin{array}{l}\text { Componentes norteadores encontrados: } \\
\text { Interdiscursividade. } \\
\text { Análise crítica: } \\
\text { - Controles burocráticos invisíveis (Confusa", } \\
\text { "muito confusa"). } \\
\text { - A modelagem da burocracia ("parece que tá } \\
\text { mudando"). } \\
\text { - Autonomia envolvida com procedimentos } \\
\text { antiéticos nocivos } \\
\text { ("Comportamentalmente, mentalmente e } \\
\text { tecnicamente"). }\end{array}$ \\
\hline
\end{tabular}




\begin{tabular}{|c|c|c|}
\hline 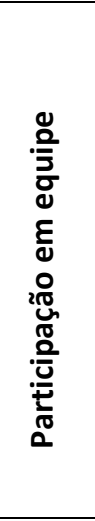 & $\begin{array}{l}\text { "(...), todo dia a gente tem reunião de } \\
\text { quinze minutos na equipe, mas nem todo } \\
\text { mundo consegue falar assim, aquilo que } \\
\text { realmente que tá pensando, então eu } \\
\text { tento fazer essas situações mais } \\
\text { individuais pra que as pessoas não tenham } \\
\text { constrangimentos e digam alguma coisa } \\
\text { que não tá agradando, ou alguma coisa } \\
\text { que possa melhorar, mas isso é uma coisa } \\
\text { que eu faço, não sei se todo mundo faz" } \\
\text { (G14). }\end{array}$ & $\begin{array}{l}\text { Componentes norteadores encontrados: } \\
\text { Interdiscursividade. } \\
\text { Análise crítica: } \\
\text { - Trabalho em equipe: estratégia de controles } \\
\text { burocráticos ("todo dia a gente tem reunião } \\
\text { de quinze minutos na equipe"). } \\
\text { - Política do silêncio: ação estratégica do } \\
\text { indivíduo, resistência e indício de sabotagem } \\
\text { (“nem todo mundo consegue falar assim, } \\
\text { aquilo que realmente que tá pensando"). } \\
\text { - Relações de poder: ações antiéticas que } \\
\text { cercam a autonomia ("constrangimentos"). }\end{array}$ \\
\hline $\begin{array}{l}\text { ¿ } \\
\text { ㅇㅇㅁ }\end{array}$ & $\begin{array}{l}\text { “Manda quem pode [risos], obedece } \\
\text { quem tem juízo" (BA1). } \\
\text { “É como eu digo, eu tenho que chegar pro } \\
\text { meu gestor olhe isso (...) não acho que isso } \\
\text { seja autonomia, não é 70\%, não tem } \\
\text { gestor que tenha 100\% de autonomia } \\
\text { não" (GI2). } \\
\text { “Foi uma maquiagem perfeita, a gente } \\
\text { tirou essa certificação (FBR nível C), acho } \\
\text { que todo mundo desenhando as coisas, } \\
\text { não é exatamente o que acontece no dia- } \\
\text { dia da gente, houve esse todo um trabalho } \\
\text { cenográfico" (GI5). }\end{array}$ & $\begin{array}{l}\text { Componentes norteadores encontrados: } \\
\text { Interdiscursividade, Provérbio, Intertextualidade } \\
\text { manifesta, Transitividade, Ethos. } \\
\text { Análise crítica: } \\
\text { - Liderança autoritária: abuso do poder } \\
\text { ("Manda quem pode [risos], obedece quem } \\
\text { tem juízo" - provérbio). } \\
\text { - Autonomia outorgada como uma } \\
\text { manipulação do poder ("eu digo, eu tenho } \\
\text { que chegar pro meu gestor olhe isso", "não } \\
\text { acho que isso seja autonomia"). } \\
\text { - A autonomia é confrontada com os princípios } \\
\text { éticos ("maquiagem perfeita", "a gente", essa } \\
\text { certificação", "todo mundo", "trabalho } \\
\text { cenográfico"). }\end{array}$ \\
\hline 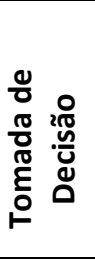 & $\begin{array}{l}\text { “Delegam, mas a gente trabalha com um } \\
\text { cronograma, tem o cronograma que é } \\
\text { feito pelo gerente de projetos. Às vezes } \\
\text { acontece esse negócio de: o cliente teve } \\
\text { uma urgência tal aqui se tira, que não sei } \\
\text { que lá, desorganiza um pouco" (BA1). }\end{array}$ & $\begin{array}{l}\text { Componentes norteadores encontrados: } \\
\text { Produção, distribuição e consumo do texto. } \\
\text { Análise crítica: } \\
\text { - Controles tecnológicos sustentados pela } \\
\text { "burocracia produto do serviço' } \\
\text { ("cronograma", "cliente", "urgência"). }\end{array}$ \\
\hline
\end{tabular}

Fonte: Elaborado pelos autores.

Quanto à ETI2, estrategicamente ela apresenta um sofisticado controle burocrático visível e invisível ('mix' de controle) operacionalizado pela gestão da qualidade que garante o cumprimento das normas, das regras e das convenções sociais. A estrutura é reprodutora de um sistema social de dominação, submissão e alienação que atua sobre as garantias sociais (BOLTANSKI; CHIAPELLO, 2009; EVERAERE, 1999b; PRESTES MOTTA, 1981; ROSENFIELD; ALVES, 2011). A organização do trabalho exibe práticas do movimento de racionalização do trabalho disfarçadas pelo hipermoderno neoautoritarismo da flexibilidade e da possibilidade da autonomia (WILLMOTT, 1993). O trabalho é percebido como fonte de escravidão e servidão, gerando a dependência e a obediência do indivíduo. A empresa adota políticas contraditórias e dúbias que ignoram as necessidades legítimas das pessoas para garantir a hegemonia (PAGÈS et al., 2008).

A atuação das lideranças evidenciam práticas autoritárias e de comportamento antiético e nocivo que atacam eficazmente a identidade profissional e social do indivíduo (SAINSAULIEU, 1977), provocando uma tensão de forças caracterizadas como pulsão de vida e pulsão de morte (FREUD, 1976). A luta entre as duas pulsões leva ao abuso do poder, de modo que a confiança é percebida como imposição e adestramento. Essas condições não permitem observar nenhuma abordagem contemporânea da liderança e da distribuição do poder, pois o trabalho em equipe é um disfarce dos controles burocráticos. 
Existe um clamor simbólico e imaginário pela liberdade, pelo empoderamento e pela apropriação do trabalho, uma vez que a pulsão de morte está difícil de combater. Essa pulsão estabelece a invisibilidade, a marginalização, a exclusão, a fragilização da identidade e a banalização da injustiça social, ocasionando o sofrimento físico e psíquico que força o indivíduo a adotar a política do silêncio (ORLANDI, 1993) como forma de proteção, para evitar a exaustão emocional. A política do silêncio é também um indício de sabotagem praticada pela organização informal. As relações de poder fragilizam psiquicamente o indivíduo como pessoa, despersonalizando-o (DEJOURS, 2011; ROSENFIELD, 2004).

A autonomia está aprisionada e subjugada às regras, cercada por políticas antiéticas, e é usada como manobra e manipulação do poder. Ela é concedida para determinadas posições hierárquicas e reservada para uma elite de profissionais (MINTZBERG, 2011) conforme a burocracia produto do serviço (ZARIFIAN, 2009).

Por fim, a análise dos dados permite afirmar que existem poucas condições de expressão da autonomia na ETI2. A partir deste caso, pode-se concluir que as organizações indicadas como NFOT nem sempre permitem a autonomia, sendo pura burocracia disfarçada de NFOT. Na prática, a autonomia não se realiza, porque a liderança utiliza controles extremamente fortes que não permitem o empoderamento do funcionário e a vivência da sua autonomia. Em conclusão, a prática da autonomia no trabalho está interligada com a liderança, a estrutura organizacional, o controle e o poder.

A análise e a interpretação dos dois casos, comparados entre si têm um significado histórico e social que serve de exemplo para diversas outras situações.

\section{CONSIDERAÇÕES FINAIS}

Este estudo apresenta como pergunta de pesquisa: "como se estrutura a autonomia dos funcionários na relação estabelecida com seus líderes em novas formas de organização do trabalho (NFOT), especificamente em duas empresas de TI no Porto Digital de Pernambuco?"

Em resposta toma-se como base a compreensão de que a autonomia é um espaço de decisão e de intervenção nos processos de organização do trabalho, em que o profissional possa ter a oportunidade de participar na organização e funcionamento da empresa e influenciar as decisões (KOVÁCS, 2006). Por sua vez, as NFOT são entendidas como novos arranjos da burocracia nas organizações, incorporando elementos de flexibilidade, inovação, hierarquia mais plana, horizontalização da estrutura, competências, trabalho em equipe, autonomia, confiança nas relações, envolvimento e participação dos profissionais (CLEGG; HARRIS; HÖPFL, 2011; KOVÁCS, 2006). E a liderança é uma proposta de linguagem, não sendo propriedade exclusiva dos líderes formais, em que se evidencia um processo de construção de uma relação, por negociações, renegociações, reconstruções, ressignificados (HOSKING, 1988; HOSKING; DACHLER, 1995; HOSKING, 2006).

Partindo dos resultados da análise dos dados observou-se que a autonomia se estrutura por meio de uma identidade profissional e social do indivíduo, de forma que as suas necessidades legítimas sejam valorizadas, principalmente o prestígio genuíno pelo conhecimento e pela experiência combinados com a recompensa em benefícios salariais e sociais (SAINSAULIEU, 1977). A flexibilidade de horários, a complexidade das tarefas na resolução dos problemas, a aprendizagem, a responsabilidade, a horizontalização da hierarquia e a redução dos controles burocráticos tecnológicos são elementos das NFOT favoráveis ao exercício da autonomia. As relações de poder entre o líder e o liderado são articuladas por meio de negociações e renegociações baseadas nas necessidades de ambos 
para garantir a realização das atividades e a convivência (REYNAUD, 1988). Essas relações não estão isentas de conflitos e tensões, mas são reguladas pela afetividade, solidariedade, confiança, evidências de verdade na linguagem falada e comunicada, pelo cumprimento das promessas - esses aspectos compõem os princípios éticos nas relações sociais, equilibrando o individual e o coletivo, de forma que as possibilidades de produção de adoecimento físico e psíquico sejam mínimas. Isto foi constatado na ETI1.

A autonomia é uma construção do pensar (autoempoderamento) e do fazer autônomo (empoderamento), e do ser autônomo (identidade social). Os interesses comuns são estabelecidos pelo afeto e pelo desejo dos indivíduos de estarem juntos eticamente. Quanto maior o afeto e o bom relacionamento entre as pessoas na execução das tarefas, maior a vivência da autonomia no trabalho, visando à emancipação caracterizada pelo bem coletivo e pelo sentimento de união. Essencialmente, a autonomia confrontará o indivíduo com as ações éticas e as ações antiéticas nas dimensões microssociais e macrossociais.

A esta altura é importante destacar alguns aspectos metodológicos desta pesquisa. É necessário apontar a contribuição teórica desta pesquisa, qual seja a de destacar a natureza burocrática das NFOT, modelos organizacionais comumente citados como exemplos de superação da Burocracia (KÓVACS, 2006; MOURA, 2012; 2016); bem como sua relevância gerencial, na medida em que revela aos praticantes que, também nestes espaços, a autonomia surge sob certas condições condicionantes intrínsecas às relações de poder, cabendo ao líder um papel importante na construção distintiva destes espaços. Isto é especialmente importante em estudos sobre empresas de $\mathrm{TI}$, normalmente caracterizadas por autonomia no trabalho, rodízio de função, participação na decisão, trabalho em equipe. Por outro lado, o acesso aos liderados a partir dos líderes foi um viés inevitável porque devido à necessidade de autorização por parte destes para que chegássemos àqueles. Esta é basicamente a limitação do método usado na pesquisa. Fica, como sugestão para estudos futuros, uma abordagem metodológica que supere este limite e que pode ocorrer a partir de um estudo exclusivo com liderados.

Por fim, se as NFOT não chegam a se constituir como modelos de ruptura com a lógica burocrática, as organizações que operam daquela forma possuem peculiaridades surgidas no encontro das práticas de liderança e de autonomia. E é desta ética (do Ethos, o espaço relacional) que emerge para uma ressignificação do coletivo na sua dimensão político-social, como uma fonte de criação, reorganização e de transformação.

\section{Agradecimento}

Os autores agradecem à FACEPE e ao CNPq pelo seu apoio financeiro (ref. APQ-08876.02/14) durante a realização deste trabalho.

\section{REFERÊNCIAS}

ABARESHI, A.; MARTIN, B.; MOLLA, A. ICTS - new organizational form linkage in the australian context: theoretical model and research instrument, JISTEM - Journal of Information Systems and Technology Management. Revista de Gestão da Tecnologia e Sistemas de Informação, v. 8, n. 3, p. 515-538, Sept./Dec. 2011. DOI: http://dx.doi.org/10.1590/S1807-17752011000300001.

ALEXANDRE-BAILLY, F. L'autonomie des individus dans l'entreprise: regards croisés entre gestion et philosophie. Sarrebruck: Editions universitaires européennes, 2011. 
ARGYRIS, C. Personality and organization: the conflict between system and the individual. New York: Harper, 1957.

ANDRADE, S. P. C.; TOLFO, S. R.; DELLAGNELO, E. H. L. Sentidos do trabalho e racionalidades instrumental e substantiva: interfaces entre a administração e a psicologia.

Revista de Administração Contemporânea - RAC, Rio de Janeiro, v. 16, n. 2, art. 2, p. 200216, mar./abr. 2012. DOI: http://dx.doi.org/10.1590/S1415-65552012000200003.

BAKHTIN, M. M. Marxismo e filosofia da linguagem: problemas fundamentais do método sociológico na ciência da linguagem. 13. ed. São Paulo: HUCITEC, 2012.

BEDEIAN, A. G.; HUNT, J. G. Academic amnesia and vestigial assumptions of our forefathers. The Leadership Quarterly, v. 17, n. 2, p. 190-205, 2006. DOI:

https://doi.org/10.1016/j.leaqua.2005.12.006.

BENDASSOLLI, P. F.; MAGALHÃES, M. O.; MALVEZZI, S. Liderança nas organizações. In: ZANELLI, J, C., BORGES-ANDRADE, J. E., BASTOS, A. V. B. (org.). Psicologia, Organizações e Trabalho no Brasil. 2. ed. Porto Alegre: Artmed, 2014. p. 413-449.

BOLTANSKI, L. CHIAPELLO, E. O novo espírito do capitalismo. São Paulo: Editora WMF Martins Fontes, 2009.

BRYMAN, A. Liderança nas Organizações. In: CLEGG, S. R.; HARDY, C.; NORD, W. R.; FISCHER, T.; CALDAS, M.; FACHIN, R. (org.). Handbook de Estudos Organizacionais. 3 v. São Paulo: Atlas, 2004. p. 258-281.

CAYGILL, H. Dicionário Kant. Trad. Álvaro Cabral. Rio de Janeiro: Jorge Zahar Ed., 2000.

CAPPELLI, P.; ROGOVSKI, N. Employee involvement and organizational citizenship:

implications for labor law and "lean production". Industrial and Labor Relations Review, v. 51, n. 4, p. 633-653, 1998. DOI: https://doi.org/10.1177/001979399805100405.

CASTORIADIS, C. A instituição imaginária da sociedade. Trad. Guy Reynaud. 6. ed. Rio de Janeiro: Paz e Terra, 2007.

CHÊNEVERT, D.; DUBÉ, M. Les nouvelles formes d'organisation du travail: le rôle des perspectives contingente et institutionnelle. Relations Industrielles / Industrial Relations, v. 63, n. 1, p. 134-159, 2008. DOI: https://doi.org/10.7202/018125ar.

CLEGG, S. Organizações modernas. Celta: Oeiras, Portugal, 1998.

CLEGG, S.; HARRIS, M.; HÖPFL, H. Managing modernity: beyond bureaucracy? Reviewed by André Spicer, Oxford: Oxford University Press. M@n@gement, v. 14, n. 4, p. 252-262, 2011. DOI: https://doi.org/10.3917/mana.144.0252.

COHENDET, P.; LLERENA, P. Flexibilité et modes d'organisation. Revue Française de Gestion, n.123, p. 72-79, mars-avril-mai, 1999. 
CONGER, J.; KANUNGO, R. The empowerment process: integrating theory and practice. Academy of Management Review, v.13, n.3, p. 471-482, 1988. DOI:

https://doi.org/10.2307/258093.

COOPER, R.; BURRELL, G. Modernism, postmodernism and organizational analysis: an introduction. Organization Studies, v. 9, n.1, p. 91-112, 1988. DOI:

https://doi.org/10.1177/017084068800900112.

COURPASSON, D. Managerial strategies of domination - power in soft bureaucracies. Organization Studies. v. 21, n. 1, p. 141-161, 2000a. DOI:

https://doi.org/10.1177/0170840600211001.

L'action contrainte. Organisations libérales et domination. Paris: Presses

Universitaires de France, 2000b.

CRESWELL, J. W. Projeto de pesquisa: métodos qualitativo, quantitativo e misto. 3. ed. Porto Alegre: Artmed/Bookman, 2010.

CROZIER, M.; FRIEDBERG, E. L'acteur et le système: les contraintes de l'action collective. Paris: Éd. du Seuil, 1977.

D'ANNUNZIO-GREEN, N.; MACANDREW, J. Re-empowering the empowered - the ultimate challenge? Personnel Review, v. 28, n. 3, p. 258-278, 1999. DOI:

https://doi.org/10.1108/00483489910264615.

DECI, E. L.; RYAN, R. M. Handbook of self-determination research. New York: University of Rochester Press, Softcover edition, 2004.

DELLAGNELO, E. H. L.; MACHADO-DA-SILVA, C. L. Novas formas organizacionais: onde se encontram as evidências empíricas de ruptura com o modelo burocrático de organizações? O\&S - Organização e Sociedade, Salvador, v. 7, n. 19, p. 19-33, set./dez. 2000. DOI: http://dx.doi.org/10.1590/S1984-92302000000300002.

DEJOURS, C. A banalização da injustiça social. 7. ed. Rio de janeiro: Editora FGV, 2011.

D'INTINO, R.; GOLDSBY, M. G.; HOUGHTON, J. D.; NECK, C. P. Self-leadership: a process for entrepreneurial success. Journal of Leadership \& Organizational Studies, v. 13, n. 4, p. 105120, 2007. DOI: https://doi.org/10.1177/10717919070130040101.

DIRKS, K. T.; FERRIN, D. L. The role of trust in organizational settings. Organization Science, v. 12, n. 4, p. 450-467, 2001. DOI: https://doi.org/10.1287/orsc.12.4.450.10640.

DUNFORD, R.; PALMER, I.; BENVENISTE, J. CRAWFORD, J. Coexistence of 'old' and 'new' organizational practices: transitory phenomenon or enduring feature? Asia Pacific Journal of Human Resources, SAGE Publications, Los Angeles, v. 45, n. 1 p. 24-43, 2007. DOI : https://doi.org/10.1177/1038411107073597. 
EL ANDOULSI, S. Autonomie au travail et dynamique des échanges en entreprise. Cas du secteur textile et habillement. Editions Universitaires Européennes, 2012.

ESCRIVÃO FILHO, E.; GUERRINI, F. M. A teoria administrativa sob o enfoque dos temas organizacionais. In: ESCRIVÃO FILHO, E.; PERUSSI FILHO, S. Teorias de administração introdução ao estudo do trabalho do administrador. São Paulo: Saraiva, 2010.

EVANS, B. K.; FISCHER, D. G. A hierarchical model of participatory decision-making, job autonomy, and perceived control. Human Relations, v. 45, p. 1169-1189, 1992. DOI : https://doi.org/10.1177/001872679204501103.

EVERAERE, C. Autonomie et collectifs de travail. Lyon: Editions de l'Anact, coll. Points de repère, 1999a.

. Les effets pervers de la flexibilité quantitative. Revue Française de Gestion, n.124, juin-juil.août, 1999b.

FAIRCLOUGH, N. Discurso e mudança social. 2. ed. Brasília: Editora UNB, 2019.

FLEIG, M. Autonomia na pós-modernidade: um delírio? Cadernos IHU Ideias. Rio Grande do Sul: Instituto Humanitas Unisinos, 2007.

FLICK, U. Introdução à metodologia de pesquisa: um guia para iniciantes. Porto Alegre: Penso, 2013.

FONSECA, A. M. O.; PORTO, J. B.; BORGES-ANDRADE, J. E. Liderança: um retrato da produção científica brasileira. Revista de Administração Contemporânea - RAC, Rio de Janeiro, v. 19, n. 3, art. 1, p. 290-310, maio/jun. 2015. DOI: http://dx.doi.org/10.1590/19827849 rac20151404.

FOSS, N. J. Introduction: New Organizational Forms - critical perspectives. International Journal of the Economics of Business, v. 9, n. 1, p. 1- 8, 2002.

DOI: https://doi.org/10.1080/13571510110102949.

FRENCH, J. R.. P.; RAVEN, B. Les bases du pouvoir social. Psychologie sociale - textes fondamentaux, anglais et américains, p. 359-377, 1965.

FREUD, S. Obras psicológicas completas. Volume XVIII (1920-1922). Rio de Janeiro. Imago Editora Ltda, 1976.

GAGNÉ, M.; DECI, E. L. Self-determination theory and work motivation. Journal of Organizational Behavior, v. 26, p. 331-362, 2005. DOI: https://doi.org/10.1002/job.322.

GERGEN, K. J.; TOJO, J. G. M. Organizational science in a postmodern context. Journal of Applied Behavioral Science, n. 32, p. 356-378, 1996. DOI:

http://dx.doi.org/10.4135/9781446219645.n10. 
GIORDANO, Y. Conduire un projet de recherche: une perspective qualitative. Florence Allard-Poesi, Christiane Demers, Nicole Giroux... et al.] ; coordonné par Yvonne Giordano. Colombelles (Calvados): EMS management \& société, 2003.

GRAEN, G. B.; UHL-BIEN, M. The transformation of professionals into self-managing and partially self-designing contributors: toward a theory of leadership-making. Journal of Management Systems, v. 3, n. 3, p. 25-39, 1991.

GRAETZ, F.; SMITH, A. C. T. Duality theory and organizing forms in change management. Journal of Change Management, v. 9, n. 1, p. 09-25, 2009.

DOI: https://doi.org/10.1080/14697010902727146.

GRONN, P. Distributed properties: a new architeture for leadership. Educacional Management \& Administration, v. 28, n. 3, p. 317-338, 2000. DOI: https://doi.org/10.1177/0263211X000283006.

GUNIA, N. La fonction ressources humaines face aux transformations organisationnelles des entreprises - impacts des nouvelles technologies d'information et de communication.2002. Thèse (Doctorat en Sciences de Gestion) - Université des Sciences Sociales - Toulouse I, France, 2002.

HARDY, C.; LEIBA-O'SULLIVAN, S. The power behind empowerment: implications for research and practice. Human Relations, v. 51, n. 4, p. 451-483, 1998.DOI:

https://doi.org/10.1023/A:1016989830806.

HERRENKOHL, R. C.; JUDSON, G. T.; HEFFNER, J. A. Defining and measuring employee empowerment. Journal of Applied Behavioral Science, v. 35, n. 3, p.373-389, 1999. DOI: https://doi.org/10.1177/0021886399353008.

HOLLANDER, E. P. Leadership dynamics: a practical guide to effective relationships. Free Press, New York, 1978.

HOSKING, D. M. Organizing, leadership and skilful process. Journal of Management Studies, v. 25, n. 2, p. 147-166, 1988. DOI: https://doi.org/10.1111/j.1467-6486.1988.tb00029.x.

Not leaders, not followers: a post-modern discourse of leadership processes. In: SHAMIR, B.; BLIGH, M.; UHL-BIEN, M. (ed.). Follower - centered perspectives on leadership: a tribute to the memory of James R. Meindl. Greenwich, CT: Information Age Publishing, 2006.

HOSKING, D. M.; DACHLER, H. P. The primacy of relations in socially constructing organizational realities. In: HOSKING, D. M.; DACHLER, H. P.; GERGEN, K. J. (ed.). Management and organisation: relational perspectives. Ashgate/Avebury, 1995. p. 1-23.

KALLINIKOS, J. Work, human agency and organizational forms: an anatomy of fragmentation. Organization Studies, v. 24, n. 4, p.595-618, 2003. DOI: https://doi.org/10.1177/0170840603024004005. 
KOVÁCS, I. Novas formas de organização do trabalho e autonomia no trabalho. Sociologia, Problemas e Práticas, n. 52, p. 41-65, 2006.

LALANDE, A. Vocabulaire technique et critique de la philosophie. 2a édition Quadrige: Presses universitaires de France, DL, 2006.

LANGFRED, C. W. Too much of a good thing? Negative effects of high trust and individual autonomy in self-managing teams. Academy of Management Journal, v. 47, n. 3, p. 385-399, 2004. DOI: https://doi.org/10.5465/20159588.

LE BOTERF, G. De la compétence - essai sur um attracteur étrange. In: Les éditions d'organisations. Paris: Quatrième Tirage, 1995.

LEVINSON, S. C. Pragmática. São Paulo: Martins Fontes, 2007.

LIMA, S. M. M. Autonomia versus heteronomia: impactos da tecnologia informacional sobre o trabalho na saúde. Revista FAE, Curitiba, v. 7, n. 1, p.103-118, jan./jun. 2004.

MALIK, S. H. A study of relationship between leader behaviors and subordinate job expectancies: a path-goal approach. Pakistan Journal of Commerce \& Social Sciences, v. 6, n. 2, p. 357-371, 2012.

MALVEZZI, S. Liderança. In: BENDASSOLLI, P. F.; BORGES-ANDRADE, J. E. (org.). Dicionário de psicologia do trabalho e das organizações. Belo Horizonte: Artesã, 2019. p. 417-423.

MANZ, C. C. Self-leadership: toward an expanded theory of self-influence processes in organizations. Academy of Management Review, v. 11, n. 3, p. 585-600, 1986. DOI: https://doi.org/10.5465/amr.1986.4306232.

MANZ, C. C.; SIMS, H. P. JR. Self-management as a substitute for leadership: a social learning theory perspective. Academy of Management Review, v. 5, n. 3, p. 361-367, 1980. DOI: https://doi.org/10.5465/amr.1980.4288845.

MAYNARD, M. T.; GILSON, L. L.; MATHIEU, J. E. Empowerment-fad or fab? A multilevel review of the past two decades of research. Journal of Management, v. 38, n. 4, p. 12311281, 2012. DOI: https://doi.org/10.1177/0149206312438773.

MAZMANIAN, M.; ORLIKOWSKI, W. J.; YATES, J. The autonomy paradox: the implications of mobile email devices for knowledge professionals. Organization Science, v. 24, n. 5, p. 13371357, 2013. DOI: https://doi.org/10.1287/orsc.1120.0806.

MERRIAM, S. B. Qualitative research: a guide to design and implementation. ed. rev e ampl. San Francisco, CA: Jossey-Bass, 2009.

MINTZBERG, H. Criando organizações eficazes - estruturas em cinco configurações. 2. ed. São Paulo: Editora Atlas, 2011. 
MOURA, G. L.. Abusos metafóricos em manuais de introdução à administração. RAM. Revista de Administração Mackenzie (Impresso), v. 13, p. 138-167, 2012.

Relações desumanas: reflexões sobre "humanismo" e controle na relação indivíduoorganização. Farol - Revista de Estudos Organizacionais e Sociedade, v. 3, p. 163-205, 2016.

MÜLLER, G. F.; GEORGIANNA, S.; SCHERMELLEH-ENGEL, K.; ROTH, A. C.; SCHREIBER, W. A.; SAUERLAND, M.; MUESSIGMANN, M. J.; JILG, F. Super-leadership and work enjoyment: direct and moderated influences. Psychological Reports: Employment Psychology \& Marketing, v. 113, n. 3, p. 804-821, 2013. DOI: https://doi.org/10.2466/01.14.PR0.113x32z0.

NADLER, D.; TUSHMAN, M. The organization of the future: Strategic imperatives and core competencies for the 21st century. Organizational Dynamics, v. 28, n. 1, p. 45-60, 1999. DOI: https://doi.org/10.1016/S0090-2616(00)80006-6.

ORLANDI, E. P. As formas do silêncio: no movimento dos sentidos. 2. ed. Campinas: Edunicamp, 1993.

PAGÈS, M.; BONETTI, M.; GUALEJAC, V.; DESCENDRE, D. O poder das organizações. São Paulo: Atlas, 2008.

PAIVA JÚNIOR, F. G.; LEÃO, A. L. M. S.; MELLO, S. C. B. Validade e confiabilidade na pesquisa qualitativa em Administração. Revista de Ciências da Administração, v. 13, n. 31, p. 190-209, set./dez. 2011. DOI: https://doi.org/10.5007/21758077.2011v13n31p190.

PALMER, I.; DUNFORD, R. Out with the old and in with the new? The relationship between traditional and new organizational practices. The International Journal of Organizational Analysis, v. 10, n. 3, p. 209-225, 2002. DOI:

https://doi.org/10.1108/eb028950.

PALMER, I.; BENVENISTE, J.; DUNFORD, R. New Organizational Forms: towards a generative dialogue. Organization Studies, v. 28, n. 12, p. 1829-1847, 2007. DOI:

http://dx.doi.org/10.1177/0170840607079531.

PARKER, M. Post-moderm organizations or postmodern organization theory? Organization Studies, v. 13, n. 1, p.35-54, 1992. DOI: https://doi.org/10.1177/017084069201300103.

PÊCHEUX, M. Semântica e discurso: uma crítica à afirmação do óbvio. 5. ed. São Paulo: UNICAMP, 2016.

PINCHOT, G.; PINCHOT, E. The end of bureaucracy and the rise of the intelligent organization. San Francisco: Berrett-Koehler, 1994.

PRESTES MOTTA, F. C. O poder disciplinar nas organizações formais. Revista de Administração de Empresas - RAE, São Paulo, v. 21, n. 4, p. 33-41, out./dez.1981. DOI: 
http://dx.doi.org/10.1590/S0034-75901981000400003.

PURSER, R.; CABANA, S. The self-managing organization. New York: Free Press, 1998.

QUINN, J. B. The intelligent enterprise a new paradigm. Academy of Management Executive, v. 6, n. 4, p. 48-63, 1992.

REYNAUD, J-D. Les régulations dans les organisations: régulation de contrôle et régulation autonome. Revue Française de Sociologie, v. 29, n. 1, p. 5-18, 1988.

ROMANELLI, E. The evolution of new organisational forms. Annual Review of Sociology, $v$. 17, n. 1, p. 79-103, 1991. DOI: https://doi.org/10.1146/annurev.so.17.080191.000455.

ROSENFIELD, C. L. Autonomia outorgada e apropriação do trabalho. Sociologias, Porto Alegre, ano 6, n. 12, p. 202-227, jul./dez. 2004. DOI: http://dx.doi.org/10.1590/S151745222004000200008 .

ROSENFIELD, C. L.; ALVES, D. A. Autonomia e trabalho informacional: o teletrabalho. Revista de Ciências Sociais, Rio de Janeiro, v. 54, n. 1, p. 207-233, 2011. DOI:

http://dx.doi.org/10.1590/S0011-52582011000100006.

ROSS, L.; RIX, M.; GOLD, J. Learning distributed leadership: part 1. Industrial and Commercial Training, v. 37, n. 3, p. 130-137, 2005. DOI: https://doi.org/10.1108/00197850510593737.

ROST, J. C. Leadership: a discussion about ethics. Business Ethics Quarterly, v. 5, n. 1, p. 129142, 1995. DOI: https://doi.org/10.2307/3857276.

ROTTER, J. B. Interpersonal trust, trustworthiness, and gullibility. American Psychologist. v. 35, n. 1, p. 1-7, 1980. DOI: http://doi.apa.org/getdoi.cfm?doi=10.1037/0003-066X.35.1.1.

SAINSAULIEU, R. L'identité au travail: les effets culturels de l'organisation. 1e édition. Paris: Presses de la Fondation nationale des sciences politiques, 1977.

SERVIÇO BRASILEIRO DE APOIO ÀS MICRO E PEQUENAS EMPRESAS - SEBRAE. Anuário do trabalho nos pequenos negócios 2016. 9. ed. São Paulo- SP: DIEESE, 2018. p. 17. Disponível em:

https://m.sebrae.com.br/Sebrae/Portal\%20Sebrae/Anexos/Anu\%C3\%A1rio\%20do\%20Trabal ho\%20nos\%20Pequenos\%20Neg\%C3\%B3cios\%202016\%20VF.pdf. Acesso em: 30 nov. 2019.

SMITH, A. C.; MOULY, V. S. Empowerment in New Zealand firms: insights from two cases. Empowerment in Organizations, v. 6, n. 3, p. 69-80, 1998. DOI: https://doi.org/10.1108/14634449810210814.

SOBRAL, F.; FURTADO, L. A liderança pós-heroica: tendências atuais e desafios para o ensino de liderança. Revista de Administração de Empresas - RAE, São Paulo, v. 59, n. 3, p. 209214, maio-jun. 2019. DOI: http://dx.doi.org/10.1590/s0034-759020190306. 
SPENCER, L. M. JR.; SPENCER, S. M. Competence at work: models for superior performance. New York: John Wiley, 1993.

SPILLANE, J. P.; SHERER, J. Z. Towards a theory of leadership practice: A distributed perspective. Curriculum Studies, v. 36, n. 1, p. 3-34, 2004. DOI: https://doi.org/10.1080/0022027032000106726.

SPILLANE, J. P.; HALVERSON, R.; DIAMOND, J. B. Investigating school leadership practive: a distributed perspective. Education Researcher, v. 30, n. 3, p. 23-28, 2001.

DOI: https://doi.org/10.3102/0013189X030003023.

TARONDEAU, J-C. Introduction: approches et formes de la flexibilité. Revue Française de Gestion, n. 123, p. 65-119, maio, 1999.

TENÓRIO, F. G. Flexibilização organizacional - mito ou realidade? 2. ed. Rio de janeiro: Editora Fundação Getúlio Vargas, 2002.

TERSSAC, G. Autonomie dans le travail. Paris, PUF, 1999.

Autonomie dans le travail. In: BEVORT, A.; JOBERT, A.; LALLEMENT, M.; MIAS, A. (s/d). Dictionnaire du travail, Paris: PUF, coll Quadrige, 2012. p. 47-53.

THOMAS, K. W.; VELTHOUSE, B. A. Cognitive elements of empowering: an interpretive model of intrinsic task motivation. Academy of Management Review, v. 15, n. 4, p. 666-681, 1990. DOI: https://doi.org/10.5465/amr.1990.4310926.

TSOUKAS, H. Postmodernism, reflexive rationalism and organizational studies: a reply to Martin Parker.Organization Studies, v. 13, n. 4, p. 643-650, 1992. DOI: https://doi.org/10.1177/017084069201300407.

TURANO, L. M.; CAVAZOTTE, F. Conhecimento científico sobre liderança: uma análise bibliométrica do acervo do The Leadership Quarterly. Revista de Administração Contemporânea - RAC, Rio de Janeiro, v. 20, n. 4, art. 3, p. 434-457, jul./ago. 2016. DOI: http://dx.doi.org/10.1590/1982-7849rac2016140075.

UHL-BIEN, M. Relational leadership theory: exploring the social process of leadership and organizing. The Leadership Quarterly, v. 17, n. 6, p. 654-676, 2006. DOI: https://doi.org/10.1016/j.leaqua.2006.10.007.

UHL-BIEN, M.; GRAEN, G. B.; SCANDURA, T. A. Implications of leader-member exchange (LMX) for strategic human resource management systems: relationships as social capital for competitive advantage. In: FERRIS, G.R. (ed.). Research in personnel and human resource management, v. 18, Greenwich, CT: JAI Press, Jan. 2000. p. 137-185.

VARELA, F. Autonomie et connaissance: essai sur le vivant. Paris: Seuil. (Tradução ampliada do original em inglês de 1980), 1989. 
VILAS-BOAS, O. T.; DAVEL, E. P. B. Prática intercultural da liderança: princípios e desafios da pesquisa empírica. Teoria e Prática em Administração, v. 8, n. 1, p. 106-137, 2018. DOI: http://dx.doi.org/10.21714/2238-104X2018v8i1-35514.

VOLBERDA, $\mathrm{H}$. Toward the flexible form: how to remain vital in hypercompetitive environments. Organization Science, v. 7, n. 4, p. 359-374, 1996.

DOI: https://pubsonline.informs.org/doi/10.1287/orsc.7.4.359.

WEBER, M. Os três tipos puros de dominação legítima. Tradução de Gabriel Cohen. Rio de Janeiro: Guedes Multimídia, 2008.

WILLMOTT, $\mathrm{H}$. Strength is ignorance; slavery is freedom: managing culture in modern organizations. Journal of Management Studies, v. 30, n. 4, p. 515-552, 1993.

DOI: https://doi.org/10.1111/j.1467-6486.1993.tb00315.x.

YUN, S., COX, J.; SIMS, H. P. The forgotten follower: a contingency model of leadership and follower self-leadership. Journal of Managerial Psychology, v. 21, n. 4, p. 374-388, 2006. DOI: https://doi.org/10.1108/02683940610663141.

ZARIFIAN, P. Objectif compétence. Pour une nouvelle logique. Première édition. RueilMalmaison: Éd. Liaisons, 1999a.

. L'autonomie comme confrontation coopératrice à des enjeux. In: CHATZIS, K., MOUNIER, C., VELTZ, P.; ZARIFIAN, P. (Coord.). L'autonomie dans les organisations. Quoi de neuf? Paris: L'Harmattan, 1999b. p. 39-64.

Le travail et la compétence: entre puissance et contrôle. 1re édition. France: Presses Universitaire France (PUF), 2009.

ZATTI, V. Autonomia e educação em Immanuel Kant e Paulo Freire. Porto Alegre: EDIPUCRS, 2007. 